(4) $B^{b^{n}}$ MASTER

\title{
Methodology and Basic Algorithms of the Livermore Economic Modeling System
}

Robert B. Bell

March 17, 1981 


\section{DISCLAIMER}

This report was prepared as an account of work sponsored by an agency of the United States Government. Neither the United States Government nor any agency Thereof, nor any of their employees, makes any warranty, express or implied, or assumes any legal liability or responsibility for the accuracy, completeness, or usefulness of any information, apparatus, product, or process disclosed, or represents that its use would not infringe privately owned rights. Reference herein to any specific commercial product, process, or service by trade name, trademark, manufacturer, or otherwise does not necessarily constitute or imply its endorsement, recommendation, or favoring by the United States Government or any agency thereof. The views and opinions of authors expressed herein do not necessarily state or reflect those of the United States Government or any agency thereof. 


\section{DISCLAIMER}

Portions of this document may be illegible in electronic image products. Images are produced from the best available original document. 


\section{DISCLAIMER}

This document was prepared as an account of work sponsored by an agency of the United States Government. Neither the United States Government nor the University of California nor any of their employees, makes any warranty, express or implied, or assumes any legal liability or responsibility for the accuracy, completeness, or usefulness of any information, apparatus, product, or process disclosed, or represents that its use would not infringe privately owned rights. Reference herein to any specific commercial products, process, or service by trade name, trademark, manufacturer, or otherwise, does not nccessarily constitute or imply its endorsement, recommendation, or favoring by the United States Government or the University of California. The views and opinions of authors expressed herein do not necessarily state or reflect those of the United States Government thereof, and shall not be used for advertising or product endorsement purposes.

Work performed under the auspices of the U.S. Department of Energy by Lawrence Livermore National Laboratory under Contract W-7405-Eng-48. 
UCRL-53131

Distribution Category UC-95c

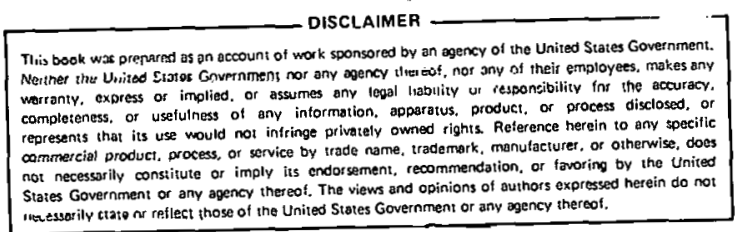

\title{
Methodology and Basic Algorithms of the Livermore Economic Modeling System
}

\author{
Robert B. Bell
}

Manuscript date: March 17, 1981

\section{LAWRENCE LIVERMORE LABORATORY University of California $\bullet$ Livermore, California $\bullet 94550$}




\section{FOREWORD}

About a year ago I began the project of writing a report to describe in detail the methodology and algorithms used in the Livermore Economic Modeling System (EMS). Because of more pressing obligations on me, the report has languished in a half-completed state for many months. During that period, I released separate documents which outline two of the most important EMS algorithms-the resource-pricing process ${ }^{1}$ and the market allocation scheme. ${ }^{2}$ It occurred to me that the completed sections of the methodology and algorithm document detailed most of the other essential EMS algorithms, in particular the basic pricing scheme on which all other EMS pricing algorithms are based. Therefore, in the interest of making the information available, I have decided to publish those completed sections as this report.

This report, together with Refs. 1 and 2, provide documentation for all but a few specialized EMS algorithms. These algorithms, not documented here, are electric power loading, price and quantity controls, the refinery simulation process, secondary materials submodel, and the end-use market self-elasticity submodel. These algorithms are of sufficient individual interest and importance that I intend to prepare a separate report on each of them. 


\section{CONTENTS}

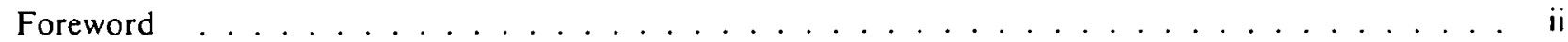

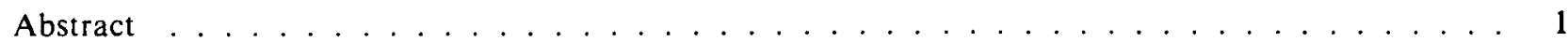

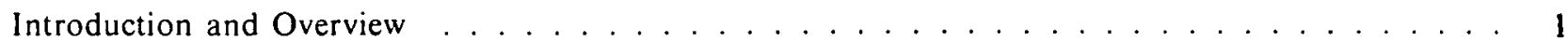

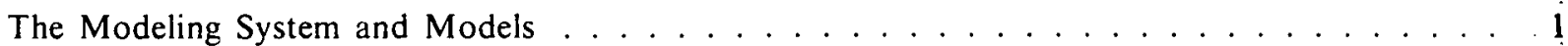

Network Models . . . . . . . . . . . . . . . . . . . . . . . . . . . 2

Dynamic, Time Dependent Models . . . . . . . . . . . . . . . . . 2

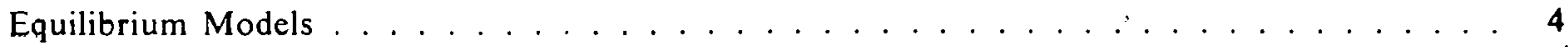

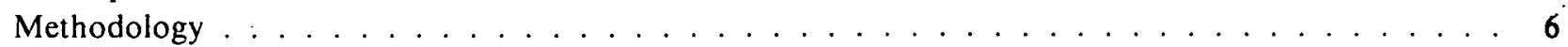

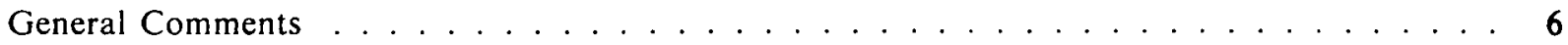

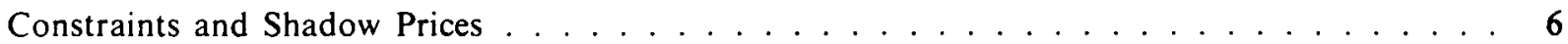

Notations and Conventions . . . . . . . . . . . . . . . . . . . . 7

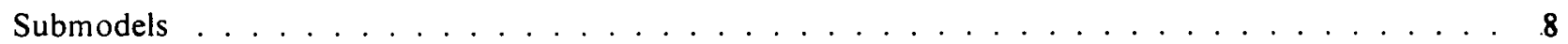

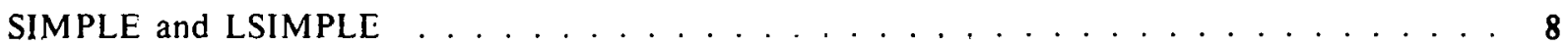

Quantity Calculation . . . . . . . . . . . . . . . . . . . 9

Price Calculation . . . . . . . . . . . . . . . . . . 13

Components of $\operatorname{pvfix}(n)$ and $\operatorname{pvo(n)} \ldots \ldots \ldots \ldots \ldots \ldots$

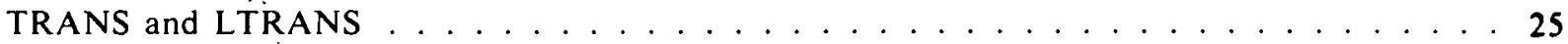

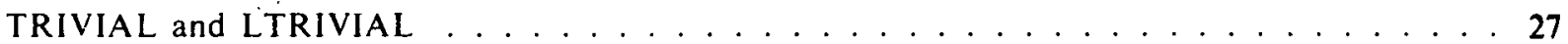

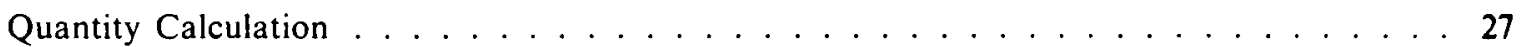

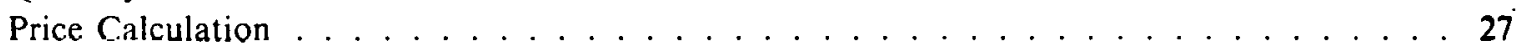

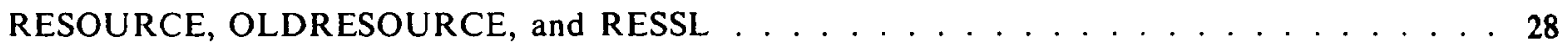

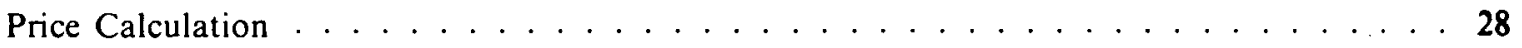

Quantity Calculation . . . . . . . . . . . . . . . . 35

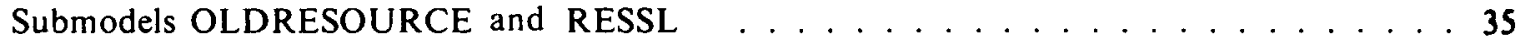

Appendix A. Calculations for NPVDCF and for Initialization of Eq. (64a) . . . . . . . . . . 37

Section 1-Calculations for Net Present Value Discounted Cash Flow (NPVDCF) . . . . . . 37

Section 2-Initialization of Cumulative Committed Capacity for Resources-Eq. (64a) . . . . 38

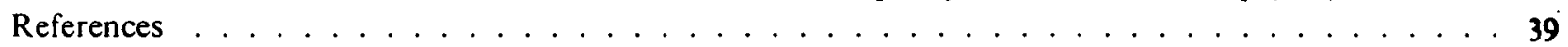




\title{
Methodology and Basic Algorithms of the Livermore \\ Economic Modeling System
}

\begin{abstract}
This report describes the methodology and the basic pricing algorithms used in the Livermore Economic Modeling System (EMS). It is directed primarily at those individuals who need to understand the derivations of the EMS equations in detail; however, it should also serve as a general introduction to the modeling system. The report will be of limited value to those totally unfamiliar with EMS and its uses in support of Energy Policy Models. Preparatory reading for such individuals is included in the references. Reference 3 is suggested as a particularly good introduction to EMS and its uses.

This report opens with a brief but comprehensive explanation of what EMS is and does, and how it does it. The report's second part examines the basic pricing algorithms currently implemented in EMS. Each algorithm's function is analyzed and a detailed derivation of the actual mathematical expressions used to implement the algorithm is presented.

EMS is an evolving modeling system; improvements in existing algorithms are constantly under development and new submodels are being introduced. This report is a "snapshot" of the standard version of EMS at the time of this report's preparation. During the course of the discussions, areas currently under study and development will be considered briefly.
\end{abstract}

\section{INTRODUCTION AND OVERVIEW}

\section{THE MODELING SYSTEM AND MODELS}

The Livermore Economic Modeling System (EMS) is a set of five computer codes that has been used at LLNL to support the development and use of Energy Policy Models (EPMs).* EMS can support many models; the number is limited only by the imagination of the modeler and the memory size of the computer on which EMS is being executed. In this report the terms "model" and EPM are used in a generic sense to represent any of the possible modeling realizations of the energy sector; the expression "modeling system" refers to EMS itself.

\footnotetext{
*EMS could support other types of models. It would be necessary only to replace the current set of algorithms with those appropriate to the desired application. At LLNL, however, EMS has been used exclusively to support Energy Policy Models. More information about EMS and the uses to which it has been applied is given in Refs. 3 through 8 . This report is essentially an update and expansion of Ref. 8.
} 
The computer codes which make up EMS are:

INPUT - A special language ${ }^{4}$ has been developed that allows EMS users to specify easily and quickly all the information necessary to construct and use models. INPUT takes data in this syntactical form and prepares a computer disk file suitable for use by the main code.

SOLVE - SOLVE, the main code, reads the disk file prepared by INPUT and performs the user specified energy-related economic calculations.

PRINT - These codes present result data from SOLVE in either tabular or graphic form, as and

PLOT

DEMAND - Enduse service demands are exogenous inputs to SOLVE. This code calculates GENERATOR those demands based on GNP and populations as a function of time.

Using terms common in the economic modeling discipline, EMS:

1. Supports network models.

2. Is a dynamic, time dependent modeling system.

3. Makes decisions based on engineering economics calculations:

4. Is an equilibrium modeling system in that a supply-demand balance based on the relative prices of competitors is achieved iteratively.

\section{NETWORK MODELS}

EMS simulates the energy sector with a series of connected nodes. There are two types of nodes:

1. Process nodes-These nodes represent energy production or conversion of energy from one form to another. Examples are coal mining in Appalachia, coal-to-syncrude conversion in the Great Plains, electricity generation in New England and the heating of buildings by gas furnaces in California. Transportation processes such as gas pipelines, electric transmission lines, and unit coal trains are special types of process nodes which explicitly include the distance energy is moved. The final type of process nodes are the control processes which represent external (political, environmental, technological) constraints on prices and/or quantities of a particular energy type.

2. Market nodes-A given energy type can often be produced by more than one source. In turn, more than one consumer usually desires a share of this energy. Market nodes serve as aggregationdistribution points in the network.

An example of a portion of an EMS-supported EPM network is shown in Fig. 1.

A pictorial way of viewing a network structure of this kind is to imagine that prices and quantities for an energy type are passed along the arcs of the network from node to node. As is described more fully later, energy prices are determined at process nodes, and the allocation of energy markets to potential suppliers takes place at market nodes. Note that the explicit inclusion of distance-dependent transportation processes permits the simple and natural inclusion of geographic regional effects.

\section{DYNAMIC, TIME DEPENDENT MODELS}

The goal of EMS as applied to Energy Modeling is to calculate prices and quantities of the various energy types as a function of time. EMS actually determines these quantities at a discrete set of user-prescribed times separated by a time interval, hereafter referred to as Delta. 


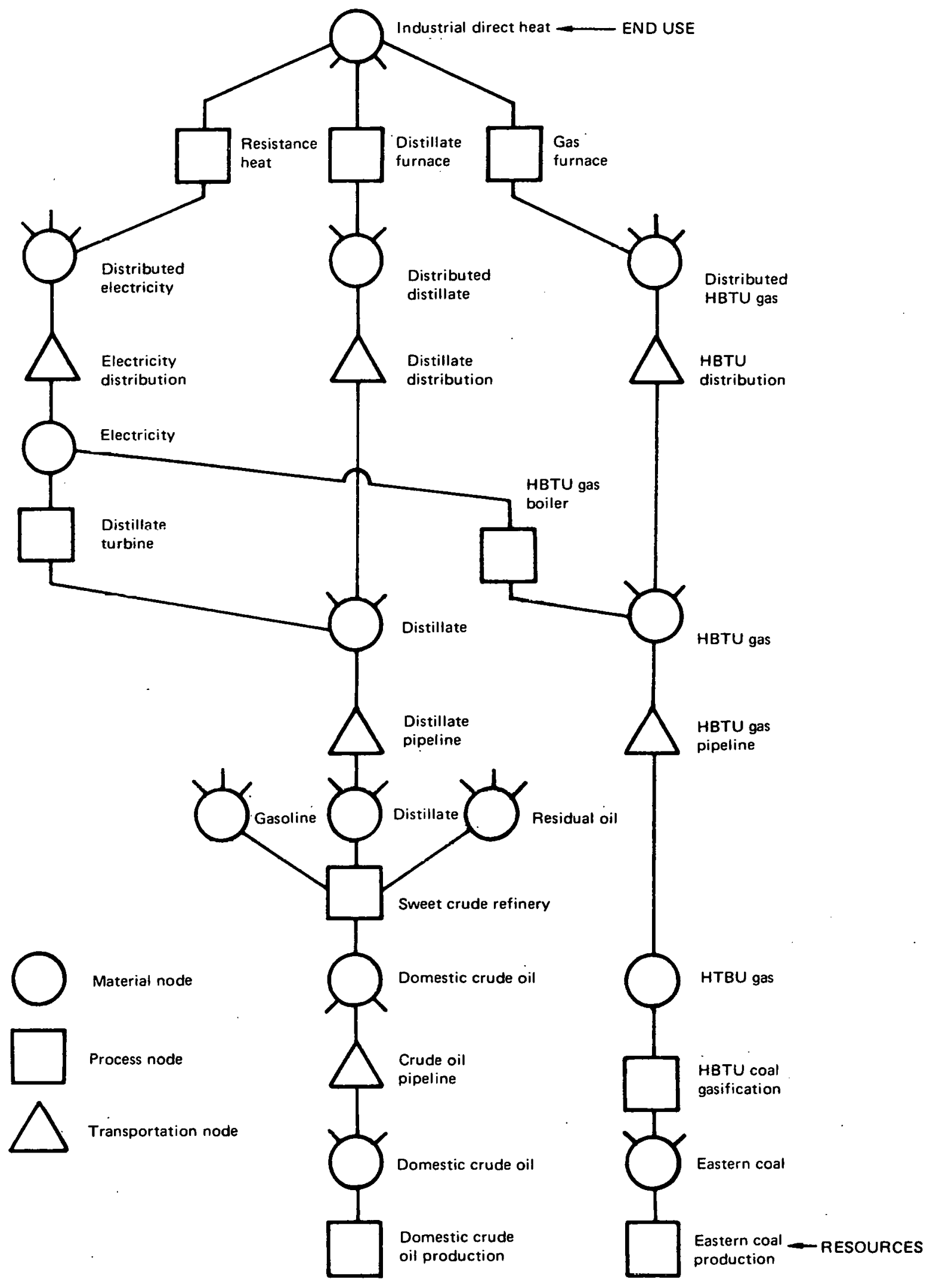

FIG. 1. A small portion of the EPM energy network. 
The starting point for EMS is a set of enduse service demands defined for each time of the problem. Examples are electric spaceheating on the East Coast, automobile miles on the West Coast, petrochemical feedstocks, and industrial process steam. These service demands are calculated by the DEMAND GENERATOR code mentioned earlier. The demands yielded by this code are based on a set of analytic equations in which the independent variables are GNP and population as a function of time. The dependent variables are enduse service demands as a function of geographic region, consuming sector (industrial, transportation, etc.), enduse, and time. Note that the enduse demands are not explicitly dependent on energy prices or quantities so there is no direct feedback of the results from EMS to the DEMAND GENERATOR code. However, the enduse service demands that EMS attempts to satisfy are affected by the EMS results in a way which will be described later in this report.

It is the job of EMS to satisfy the specified enduse demands by "producing" raw resources, "converting" energy from one form to another, and "transporting" energy from resource and conversion regions to consuming regions. In satisfying these enduse demands, EMS must simulate the energy pricing and market allocation processes. Briefly:

1. Market allocations are based on the relative prices asked by the competitive suppliers of that market. The cheapest supplier gets most, but not all, of the market. Just how rapidly the allocated market share decreases as the relative price increases is under user control. The allocation process also simulates the effects of existing capital stocks. The retirement rate of old stocks and penetration rate of new technologies and suppliers are also under user control.

2. Pricing is done by use of a Net Present Value Discounted Cash Flow (NPVDCF) calculation under the assumption that the developer of an energy-providing technology will receive the expected rate of return on investment. In addition, resource owners demand economic rent and can withhold their resources if they are not salable at the set price including the rent.

The price calculated for a given time and technology is that for the next increment of output. That is, the prices are marginal prices. Long-term competitive equilibrium is assumed-as much of a particular technology will be constructed by the model as is needed to satisfy demand at the marginal price.

3. Controls, such as government price controls or quantity allocations, are modeled in a straightforward and natural manner by introducing a decision-making, or shadow, price which is adjusted to enforce the constraint. The shadow prices are also passed along the networks arcs with the transaction prices and quantities.

A large body of information is required to accomplish the calculations implied above. Perhaps the most fundamental data required are the prices and available quantities of the various raw resources such as coal, crude oil and nuclear fuel. The NPVDCF cash flow calculations from which prices are determined use capital costs, operating and maintenance costs, tax data such as tax life and tax rates, and a whole host of other factors on which developers customarily make decisions. The thermal conversion efficiencies* relate the energy input of a given process to the resulting energy output. In general, an extensive energy-sector data base for EMS must be supplied.

\section{EQUILIBRIUM MODELS}

EMS attempts to achieve a supply-demand balance at the lowest set of prices consistent with the market-allocation scheme, but under the constraints imposed by any existing controls of price and/or quantity. The sequence of calculations accomplished by SOLVE is as follows:

\footnotetext{
- These efficiencies take into account the relative age of the various technologies which contribute to the process. For example, the overall average automobile efficiency increases over time, due to the replacement of old cars by newer, more efficient ones.
} 
1. Starting with the specified enduse demands at the top (see Fig. 1), calculations proceed downward through the networks toward the raw resource-producing nodes. Prices are held constant on this downward pass. Note that the total output from each node is known and it is the inputs that are to be calculated. At market nodes, allocations to competitive suppliers are made on the basis of their relative prices. At process nodes, the input energies are determined from the total output by use of the thermal conversion efficiencies. Calculations proceed from node to node until the resource nodes are reached, at which point enough raw resources are produced to satisfy the demands which exist at that level. This ends the down (quantity) pass.

2. Next, prices are calculated by moving upward through the network from resource to enduse nodes. On the up (price) pass, quantities as calculated by the previous down (quantity) pass remain invariant. At the raw resource nodes, prices are based on price versus a vailability data. At conversion or transportation nodes, the prices result from the NPVDCF calculations, which use:

a. Fuel prices passed up from nodes lower in the network.

b. Capital costs and opcrating costs.

c. Tax considerations.

d. Future selling prices.

In addition, numerous adjustments are made in the price determination to account for such factors as technological improvements in construction, operation or efficiencies, increasing or decreasing demands for the energy type, and need for special materials.

At a market node, the output prices are the quantity-weighted sum of the input prices to the node.

3. When the enduse nodes are again reached, the calculated prices are compared to a set of specified reference prices for each of the nodes. A self-elasticity submodel then will adjust the demands up or down depending on the relation of the calculated prices to the reference prices. The use of this self-elasticity submodel is, of course, optional.

4. Once new demands are determined, another downward pass is started. This up-down iterative process continues until the calculated quantities and prices become sufficiently stationary. At this point a supply-demand equilibrium consistent with the market allocation scheme will have been achieved.

It is necessary to discuss two features of the quantity/price calculations in greater detail:

1. Quantity calculations are performed forward in time so that the retirement of existing capital stocks and penetration of new technologies can be modeled. The user controls the retirement and penetration rates by adjusting lag parameters in the market allocation submodel. ${ }^{2}$

2. Price calculations are performed backward in time. The NPVDCF requires a set of "future perceived prices" for times greater than the time for which the price is being determined. The future perceived prices need not be the actual calculated future prices. However, the algorithm currently implemented in EMS bases the perceived prices on these calculated future prices and, therefore, they must be known. The issue of how future prices are perceived by developers and resource owners is an extremely important one in Energy Modeling. Reférence 1 contains a detailed discussion of this subject.

This ends the overview of the EMS methodology. 


\section{METHODOLOGY}

\section{GENERAL COMMENTS}

As part of the process of defining a particular model, the user must specify what calculations are to be done at each node and supply EMS with values for all the parameters present in the chosen algorithm. Each algorithm (submodel) has a symbolic name. Assignment of a submodel to a given node is done with the KIND declarative available in the model-definition language mentioned earlier. For example, the following block might be used to define part of the information needed for a coal-to-syncrude process node:

PROCESS WCOALTOCRUDE DATA
$\mathrm{SCC} / 10.00 /$
$\mathrm{OM} / .50 /$
BL / 20. /
TL / 11. /
YRAVL / 2000. / EFF / .65 /

END

LSIMPLE is the name of a particular algorithm and the calculations appropriate to that algorithm will be performed at every node representing the process WCOALTOCRUDE.* The block shown above also assigns a value of $\$ 10.00 / \mathrm{MMBtu} /$ year to the specific capital cost parameter ("SCC / $10.00 / ")$, $\$ 0.50 / \mathrm{MMBtu}$ to the operating and maintenance costs, and the indicated values to the book life, tax life, year of availability and thermal efficiencies.

The submodels are discussed in the rest of this report and are referred to by their symbolic names.

\section{CONSTRAINTS AND SHADOW PRICES}

As mentioned earlier, three quantities can be thought of as being passed from node to node along the network arcs. They are the quantity, transaction price, and shadow price. An understanding of what the shadow price is and does is essential for an understanding of the submodels.

Shadow prices are generated by the presence of controls on either quantities or prices of energy. Decisions are then made on the basis of those shadow prices, rather than transaction prices. Perhaps a concrete example would clarify the situation. Suppose that the allowed quantity of a given type of energy is less than that which would result naturally from the transaction price. The shadow price will then be raised above the transaction price until the normal EMS decision processes (made now on the basis of the shadow price rather than the transaction price) yield a quantity very nearly equal to the constraint. ${ }^{\dagger}$

\footnotetext{
*There might be, for example, a WCOALTOCRUDE node in every resource region in which western coal is produced. The reader is referred to Ref. 4 for an explanation of how the network structure is specified.

I'Strictly speaking, the quantity should be equal to the constraint value. Computational effects usually cause the final values to be slightly different from the constraint value; also, if the normal quantity (based on transaction price) does not violate the constraint, the transaction and shadow prices are equal.
} 
The constraint situation is actually rather complicated in both real life and in modeling. For example, the following are some of the possible types of constraint.

1. Quantity ceilings with no price increases allowed.

2. Quantity ceilings with price increases allowed.

3. Quantity floors despite high prices.

4. Price floors.

5. Price ceiling with mandatory allocations.

6. Set quantities at set prices.

Case 1 corresponds to government quantity allocations and price controls to protect the consumer from the higher prices that normally accompany shortages; case 2 is similar, but with the marketplace being allowed to determine prices in times of shortage. Cases 3 and 6 have realizations today, namely, in importation of high-priced natural gas from Canada and Mexico.

In EMS, shadow prices are used in several ways. If shadow prices are present, EMS makes market allocations based on those prices. Conversion processes can:

1. Use input shadow prices for the fuel costs used to calculate output shadow prices and input transaction prices to determine output transaction prices; or

2. Use input shadow prices to calculate the output transaction price and, at the same time, yield no shadow price; or

3. Not use the shadow prices at all.

Thus, the overall effect of constraints and the resulting shadow prices depend on how the various processes are linked together.

\section{NOTATIONS AND CONVENTIONS}

Variables which are directly defined by the modeler have all capital letters; variables simply and directly derived from user-defined quantities have an initial capital letter. With a few exceptions, notably quantities and transaction and shadow prices (denoted Qin, Qout, Pin, Pout, Lin, Lout), all other variables begin with lower case letters. The various variables may be scalars, functions of time, or arc, or time and arc, or time and/or arc and other variables. A subscript $i$ always refers to the $i^{t^{\text {th }}}$ arc; subscript $n$ means the $n^{\text {th }}$ time period. Other subscripts are defined in the text. I will not be pedantic about the use of subscripts and will freely drop any subscript not essential for the derivation under consideration. Any time a subscript is deleted, it should be understood that the expression at hand holds for all values of the deleted subscript. However, there will be a full display of subscripts in the final expressions derived for a particular variable.

Certain variables are used throughout the remainder of the report and are summarized here for convenience:

\begin{tabular}{|c|c|c|}
\hline Delta & $=$ & $\begin{array}{l}\text { Time step between the user-defined problem times. Most models used at LLNL } \\
\text { have Delta }=5 \text { years. }\end{array}$ \\
\hline Time $(n)$ & $=$ & The year at the $\mathrm{n}^{\text {th }}$ time period, e.g., Time $(3)=1985$ \\
\hline Nper & $=$ & Number of time periods. \\
\hline Taxr & $=$ & Income tax rate. \\
\hline $\operatorname{Xinfl(n)}$ & $=$ & $\begin{array}{l}\text { Continuous inflation rate of period } n \text { derived from the user-defined discrete infla- } \\
\text { tion rate, } \operatorname{AINFL}(n) .[1+\operatorname{AINFL}(n)=\operatorname{Exp}(\operatorname{Xinfl}(n)) .]\end{array}$ \\
\hline Disdel & $=$ & $\begin{array}{l}\text { Real continuous developer's discount rate as derived from the user defined dis- } \\
\text { crete discount rate, ROE. }[1+\mathrm{ROE}=\operatorname{Exp}(\text { Disdel). }]\end{array}$ \\
\hline
\end{tabular}

Note that while the modeler specifies discrete inflation and discount rates, the continuous analogs will actually be used in the calculations.

Many different energy conversion processes typically appear in an Energy Model-for example, coal-to-syncrude or SNG plants, automobiles, trains, boilers, and spaceheaters. For simplicity, the term "plant" will be used for all conversion technologies. 


\section{SUBMODELS}

Submodels are referred to in this report by the symbolic name the modeler uses to bind the submodel to a particular node. Of these, SIMPLE and LSIMPLE are the most important, since they are typically the most frequently used and also form the basis for the other conversion submodels and the resource-extraction processes. A very complete description of SIMPLE and LSIMPLE is given because understanding these submodels makes it easier to understand the other submodels.

\section{SIMPLE AND LSIMPLE}

SIMPLE and LSIMPLE are basically the same submodel; they differ only in the treatment of. shadow prices. For simplicity, the single name "SIMPLE" is hereafter used for both, except when their differences are explicitly described.

SIMPLE represents conversion processes, such as cars, steam plants, synthetic crude oil plants and electric space-heaters, in which from one to five primary energy types and from one to five secondary materials are combined to yield a single energy output. (See Fig. 2.) Primary energy types are, for example, coal for coal boilers, gasoline for cars, or the sun and natural gas for a solar heater with gas backup. Secondary materials are items such as pressure vessels, boilers, or exploration equipment. In the same way plants must compete for the fuel to run them, they must also compete for equipment used to develop and build them. A large total demand from the energy sector for this equipment would imply important effects in the availability and output energy price of plants that require the equipment. These effects are captured by inclusion of a secondary material submodel.

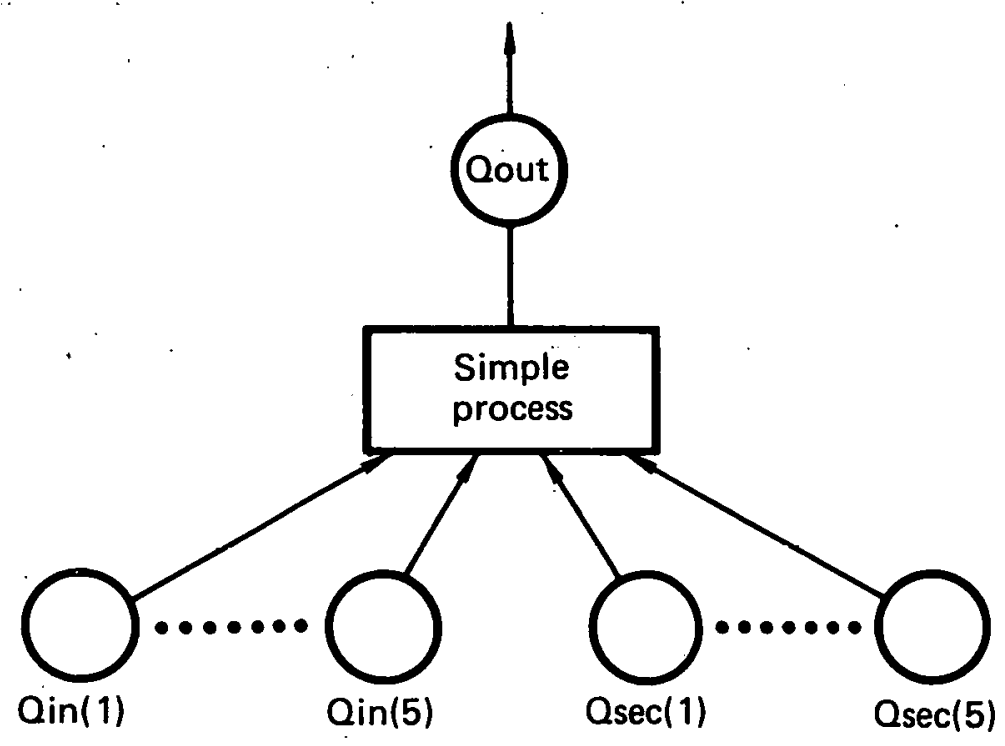

FIG. 2. The SIMPLE process. 


\section{Quantity Calculation}

Quantities are calculated on the downpass through the networks holding prices constant. Therefore, the output of each process is known. By definition, each input-energy quantity is equal to the output divided by the effective efficiency. For reasons which will become clear shortly, this definition will be written as:

$$
\operatorname{Qin}(i, n)=\frac{\text { Qout }(n)}{\operatorname{EFF}(i) \cdot v f(n)}
$$

where

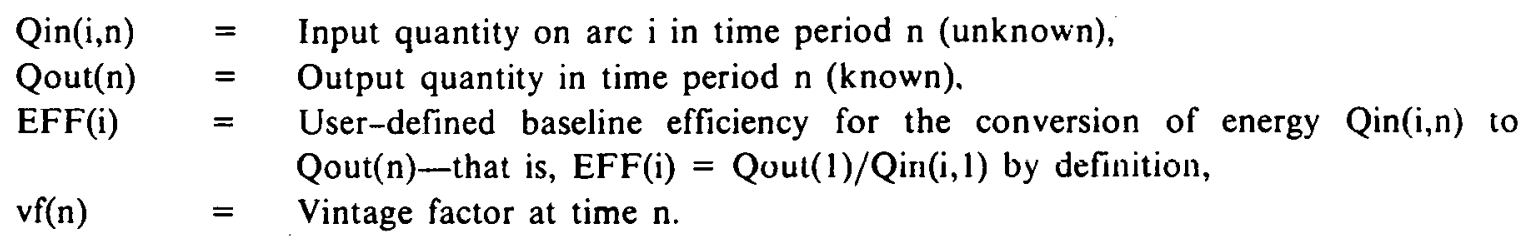

The modeler has the option of specifying that improvements in plant efficiency will take place over time. More precisely, the efficiency at time, Time $(n)($ period $n)$, is EFF - elearn $(n)^{*}$,

where

$$
\text { elearn }(n)= \begin{cases}1 & \text { Time }(n) \leqslant \text { YRAVL } \\ \left.(1-\operatorname{TCLE}) e^{-\operatorname{TCRE}[\operatorname{Time}(n)-Y R A V L}\right]+\operatorname{TCLE} & , \operatorname{Time}(n)>\text { YRAVL }\end{cases}
$$

and

TCLE = efficiency technological change limit,

TCRE = efficiency technological change rate,

YRAVL = year of availability for the technology.

The exact meaning of YRAVL will become clear shortly. It is essentially the year in which the plants in question could produce output as a mature technology.

If there is no efficiency improvement (learning) specified, vf in Eq. (1) is unity. The presence of learning greatly complicates the calculations because it becomes necessary to determine the average efficiency of the set of plants actually present in each period. Since EMS conceptually "builds" plants during the normal course of computations, it is possible to make this determination.

The reader should remember that calculations are performed at a set of discrete times, Time(n). From this point of view, an expression relating the total plant capacity at period $n, \operatorname{cap}(n)$, to the capacity in the previous period, $\operatorname{cap}(n-1)$, can be written:

$$
\operatorname{cap}(n)=\operatorname{cap}(n-1)+\operatorname{con}(n)-w(n)
$$

where

$$
\begin{aligned}
& \operatorname{con}(n)=\text { plant construction at period } n \\
& w(n)=\text { plant wear-outs at period } n .
\end{aligned}
$$

\footnotetext{
*The appearance of a subscripted variable without a subscript implies that the expression holds for all values of the subscript. In this case, the same learning is applied to the efficiencies of all primary input energies.
} 
The user-defined plant life, BL, is rounded to an integral number of time periods:

$$
\mathrm{ibl}=\text { round }(\mathrm{BL} / \text { Delta })
$$

Plants built in some period $\mathrm{n}$ are assumed to wear out exactly ibl periods later so that the wear-outs at period $\mathrm{n}, \mathrm{w}(\mathrm{n})$, is given by

$$
w(n)=\operatorname{con}(n-i b l)
$$

The expression for $\operatorname{con}(n)$ is

$$
\operatorname{con}(n)=\operatorname{MAX}[Q o u t(n)-\operatorname{cap}(n-1)+w(n), 0]
$$

According to Eq. (6), one must build enough new plants to satisfy any incremental demand over the capacity available in the last period, and to replace any worn-out plants. It is, of course, possible to have an overcapacity, in which case no plants need be built.

A little thought will show that Eqs. (3), (5), and (6) form a consistent set of recursive relations which can be solved for cap(n), con(n), and $w(n)$, once values for con(1), $\operatorname{cap}(1)$, and $w(n \leqslant i b l)$ are assigned. The value of cap(1) is simply set equal to the first period total output, Qout(1). Getting values for con(1) and $w(n \leqslant i b l)$ is more difficult. The point to notice in this regard is that EMS starts constructing plants in period 1 and none of these plants will wear out for ibl periods. It is only those plants constructed before the first period that will wear out during the first ibl periods. Since EMS does not explicitly calculate pre-time origin construction, it is necessary to make some kind of estimate for $\operatorname{con}(n \leqslant 1)$.*

The simplest assumption would be that for a long time before the first period there had existed a constant capacity equal to the first period output, Qout(1). There would then be an equilibrium between wearouts and construction during that time, such that

$$
\operatorname{con}(m)=w(m)=\frac{\text { Qout( }(1)}{i b l} \text { for } m \leqslant 1
$$

Therefore,

$$
w(n)=\operatorname{con}(n-i b l)=\frac{\text { Qout }(1)}{i b l} \text { for } n \leqslant i b l .
$$

EMS tries to make a better approximation of the pre-origin growth rate from the output quantities in periods 1 and 2. Define the pre-origin growth rate $r$ as

$$
r=\text { Qout(2)/Qout(1) , }
$$

\footnotetext{
* EMS starts calculations at the first time period (the time origin), $n=1$. In considering what has happened before this time period, we will conceptually set up a series of times with period numbers less than 1 .
} 
and assume that $\operatorname{cap}(\mathrm{m})$ is proportional to $\mathrm{r}^{\mathrm{m}}$ :

$$
\operatorname{cap}(m)=\operatorname{Qout}(m)=K r^{m} \text { for } m \leqslant 1
$$

Now, Eq. (3) also holds for $m \leqslant 1$, so

$$
\operatorname{Qout}(m)=\operatorname{Qout}(m-1)+\operatorname{con}(m)-w(m)
$$

Using Eqs. (5) and (8), this becomes

$$
K r^{m-1}-\operatorname{con}(m-i b l)+\operatorname{con}(m)=K r^{m}
$$

The reader can easily verify that a solution of this equation is

$$
\operatorname{con}(m)=\frac{K(r-1) r^{i b l-1+m}}{r^{i b l}-1}+\sum_{i=1}^{i b l} k_{i} \alpha_{i}^{n} \quad, m \leqslant 1
$$

where $\alpha_{i}=(1)^{1 / i b l}$.

Assuming that $r>1$, so that the first term dominates, we obtain a solution for $\operatorname{con}(m), m \leqslant 1$ and, thus, for $w(n)=\operatorname{con}(n-i b l)$ with $1 \leqslant n \leqslant i b l$ and $\operatorname{con}(1)$.

Before we summarize the results, we should mention that if Qout(1) $=0, r$ is set to unity to avoid dividing by zero. If $r$ is unity, then it is assumed that the circumstances leading to Eq. (7) hold.

In summary, the fully initialized and consistent set of equations for cap(n), w(n), and con(n) is:

- Capacity of plants

$$
\operatorname{cap}(n)= \begin{cases}\text { Qout(1) } & , \mathrm{n}=1 \\ \operatorname{cap}(\mathrm{n}-1)+\operatorname{con}(\mathrm{n})-\mathrm{w}(\mathrm{n}) & , \mathrm{n}>1\end{cases}
$$

- Plant wear-outs

$$
w(n)= \begin{cases}\frac{\text { Qout }(1)(r-1) r^{n-2}}{r^{i b l}-1} & , n \leqslant i b l \text { and } r \neq 1 \\ \text { Qout }(1) / i b l & , n \leqslant i b l \text { and } r=1 \\ \operatorname{con}(n-i b l) & , n>i b l\end{cases}
$$


- Construction of plants

$$
\operatorname{con}(n)= \begin{cases}\frac{\text { Qout }(1)(\dot{r}-1) r^{i b l-1}}{r^{i b l}-1} & , n=1 \text { and } r \neq 1 \\ \text { Qout(1)/ibl } & , n=1 \text { and } r=1 \\ \operatorname{MAX}[\text { Qout(n) }-\operatorname{cap}(n-1)+w(n), 0] & , n>1\end{cases}
$$

Enough information is now available to calculate the vintage factor, vf(n) in Eq. (1). At a time period $n$ the plants which exist are grouped according to the period in which they were built, and the value of Qin $(i, n)$ is written as

$$
\operatorname{Qin}(\mathrm{i}, \mathrm{n})=\sum_{\mathrm{j}=\mathrm{n}-\mathrm{ibl}+1}^{\mathrm{n}} \beta_{\mathrm{jn}} \cdot \operatorname{con}(\mathrm{j}) /(\operatorname{elearn}(\mathrm{j}) \cdot \operatorname{EFF}(\mathrm{i}))
$$

where $\beta_{\text {jn }}$ is a constant. If plants of different ages differ only in their relative efficiencies as expressed by elearn $(j)$, then the $\beta_{\mathrm{jn}}$ are independent of $\mathrm{j}$, the period in which the plant was built. When we rewrite $\beta_{\mathrm{jn}}$ as $L(n) / c a p(n)$, where $L(n)$ is another, as yet unspecified function of time period, and use Eq. (1), then

$$
Q \operatorname{Qin}(i, n)=\frac{L(n)}{E F F(i)} \cdot \sum_{j} \frac{\operatorname{con}(j)}{\operatorname{cap}(n)} \cdot \frac{1}{\text { elearn( })}=\frac{\text { Qout }(n)}{\operatorname{EFF(i)\cdot vf(n)}}
$$

If $L(n)$ is set equal to Qout(n), we see that the vintaging factor, $v(n)$, is given by

$$
\frac{1}{v f(n)}=\sum_{j} \frac{\operatorname{con}(j)}{\operatorname{cap}(n)} \cdot \frac{1}{\text { elearn(j)}}
$$

Since $\operatorname{con}(j) / \operatorname{cap}(n)$ is the fraction of the total capacity in period $n$ from plants built in period $j, 1 / v f(n)$ has the natural interpretation of being the vintage-weighted average reciprocal efficiency learning. $E F F(i) \cdot v f(n)$ is then the effective efficiency, including vintaging effects.

A more convenient expression for $1 / \mathrm{vf}(\mathrm{n})$ can be developed by changing the limits on the summations and adding compensating terms.

$$
\frac{1}{v f(n)}=\sum_{j=n-i b l}^{n-1} \frac{1}{\operatorname{cap}(n)} \cdot \frac{\operatorname{con}(j)}{\text { elearn(i) }}+\frac{1}{\operatorname{cap}(n)} \cdot \frac{\operatorname{con}(n)}{\text { elearn(n) }}-\frac{1}{\operatorname{cap}(n)} \cdot \frac{\operatorname{con}(n-i b l)}{\text { elearn(n-ibl) }}
$$

The summation term is just $1 / \mathrm{vf}(\mathrm{n}-1)$. All that now remains is to initialize $v f(1)$. This is done by assuming EFF(i) is the baseline or $n \leqslant 1$ efficiency. Since only plants built in period $n \leqslant 1$ contribute to vf( 1$)$ we will want $Q \operatorname{Qin}(i, 1)=$ Qout(1)/EFF(i), which can be effected by setting $v f(1)=1$. 
Summarizing, using Eq. (5),

$$
\begin{aligned}
& \operatorname{Qin}(i, n)=\frac{\text { Qout }(n)}{\operatorname{EFF}(i) \cdot v f(n)} \\
& \underset{v f(n)}{1}= \begin{cases}1.0 & , n=1 \\
\frac{1}{v f(n-1)}+\frac{1}{\operatorname{cap}(n)}\left[\frac{\operatorname{con}(n)}{\text { elearn(n) }}-\frac{w(n)}{\text { elearn(n-ibl) }}\right], & , n>1 .\end{cases}
\end{aligned}
$$

T'wo comments about the development of Eqs. (12) and (12a) are in order.

If $r$, as calculated from Qout(2)/Qout(1), is significantly less than unity, the expressions for $w(n)$ and $\operatorname{con}(n)$ tend to be pathogenic. Experience has shown that these inaccuracies do not generally distort the values of $v f(n)$ to any large degree. However, the capacity, $\operatorname{cap}(n)$, can have a considerable influence in the pricing calculations and care must be taken to ensure that errors do not arise as a result of this scheme for estimating the pre-origin growth rate. To this end, alternate values for $\operatorname{con}(1)$ and $w(n \leqslant i b l)$ can be specified by the modeler.

Equation (5) implies that plants wear out exactly ibl periods after their construction. This phenomenon does not occur in real life. A scheme is under development to distribute plant wear-out times over a number of years and also to nermit a refurbishing process.

\section{Price Calculation}

The price calculation in SIMPLE is a Net Present Value Discounted Cash Flow (NPVDCF) computation.* The unknowns in the resulting equation set are the prices at each period. The prices in any given period can be determined once a set of prices for periods later in time have been assigned. The term "assigned" is used rather than "calculated," since it is not necessary that the actual calculated future prices be used in the calculation for the "present" prices. This important point will be discussed later.

The components of the NPVDCF cash flows and the variable names assigned to them are:

1. $\operatorname{pvdebt}(\mathrm{n})$ - the present value of debt.

2. pveqty(n)-the present value of equity.

3. $\operatorname{pvdp}(\mathrm{n})$-the present value of depreciation tax credit.

4. pvrti(n)-the present value of real estate taxes and insurance.

5. XITC-investment tax credit.

6. fule(n)-fuel costs, including learning.

7. omle(n)-operating costs, including learning.

8. Income(n)-unit prices less unit operating and fuel costs.

9. SCC-specific capital cost.

Items 1 through 5 are fixed costs and are determined for one monetary unit of plant investment; items 6 through 8 are variable costs; item 9 represents the total investment required per actual (not nameplate) unit plant energy output capacity per year. (SCC is given in monetary units/energy units/time units.) These nine components are gathered together, with due regard to the algebraic signs (positive for cash inflow, negative for cash outflow), to yield a NPVDCF equation for each time period n:

$$
\operatorname{pvfix}(n)+\operatorname{pvo}(n)=0 \quad, l \leqslant n \leqslant \text { Nper, }
$$

*A brief description of NPVDCF calculations is given in Appendix A. 
where

pvfix(n) $=$ the present value of fixed costs per actual unit energy output,

$\operatorname{pvo}(n)=$ the present value of variable costs per actual unit energy output.

The variable pvfix(n) contains factors other than those listed above. These factors are intended to model market conditions and secondary materials effects and will be considered in due course of the discussion.

Some expressions needed later will now be developed. Recall that

BL $\quad=$ plant life in years,

ibl $=$ round $(B L / D e l t a)-$ the plant life in periods.

Define

$\mathbf{x b l}=\mathrm{ibl} \cdot$ Delta.

The calculations which follow use $\mathrm{xbl}$ as the useful plant life. Since $\mathrm{xbl}$ may not be equal to $\mathrm{BL}$, a correction factor is necessary. Remember that all discounting is done on a continuous, rather than discrete, basis. If a typical plant were to produce a continuous income, d, during its life, $L$, the present value of that income would be

$$
P V=\int_{0}^{L} \mathrm{de}^{-\mathrm{disdel} \cdot \mathrm{t}} \mathrm{dt}=\frac{\mathrm{d}}{\operatorname{disdel}}\left(1-\mathrm{e}^{-\mathrm{disdel} \cdot \mathrm{L}}\right)
$$

The ratio of the present value of income over the given plant life, $\mathrm{BL}$, to the rounded plant life, $x b l$, is the necessary correction factor, caf:

$$
\text { caf }=\frac{1-e^{-d i s d e l \cdot x b l}}{1-e^{-d i s d e l \cdot B L}}
$$

Of course, if $\mathrm{BL}=\mathrm{xbl}$, caf $=1.0$.

Before beginning the derivation of expressions for the various components of pvfix(n) and pvo(n), it is appropriate to comment on the form of the equations ultimately desired and the effects of inflation:

1. We will be developing an equation relating costs per unit of energy output to the prices per unit of energy output. All costs and income (and, thus, prices), are discounted to the period in which construction of the plants under consideration is being contemplated. In that context, the term "now" or "present" means that period, $\mathrm{n}$, for which calculations are in progress.

2. Great care must be exercised to correctly unfold inflation effects. There is more than one way to correctly build an NPVDCF equation set. Basically, EMS calculates the present value for period $n$ of a unit of monetary investment. Total investment is obtained by multiplying the unit investment in each period by the SCC. Therefore, the SCC should be the specific capital cost of a plant to be brought on-line in period n. As we shall see later, it is possible to change the SCC as a function of time. The total investment will be given in the 
same type of constant dollars as is the SCC. Provided that the user correctly specifies operating and maintenance costs, tax credits and variable penalties, etc., in the same dollars as the SCC, the units of all quantities in the NPVDCF equation will be constant dollars of the same type as those of the SCC.

3. In writing expressions for the components of pvfix(n), it may be helpful if the reader keeps in mind that investment, debt, tax base, and tax credits are essentially set at the time a facility is built. However, the future value of the investment, money used to pay the debt, and tax savings due to tax write-offs are effective in future inflated dollars. In EMS, inflation is "backed out" at the same time discounting is accomplished. During the course of deriving the following equations, I will use the term "time zero." This is not the first period of the overall problem-it is the construction time of the plant in question in period $n$. Starting the integrations which accomplish the discounting at this "zero time," rather than always carrying the time period n explicitly, will save endless text.

We are now ready to calculate expressions for the various components of pvfix(n) and pvo(n).

\section{Components of prfix(n) and pvo(n)}

1. Present Value of Debt on One Monetary Unit of Plant Investment. By definition, the equity fraction which the user specifies is

$$
E Q F=1-\frac{\text { debt' }^{\prime}}{\text { value }^{\prime}}
$$

where

$$
\begin{aligned}
& \text { debt' }=\text { average debt over existing plants, } \\
& \text { value }^{\prime}=\text { average total value of existing plants. }
\end{aligned}
$$

These averages are calculated by assuming that the initial debt for each plant goes to zero linearly in a time DL and the plant value goes to zero in a time xbl-see Fig. 3.

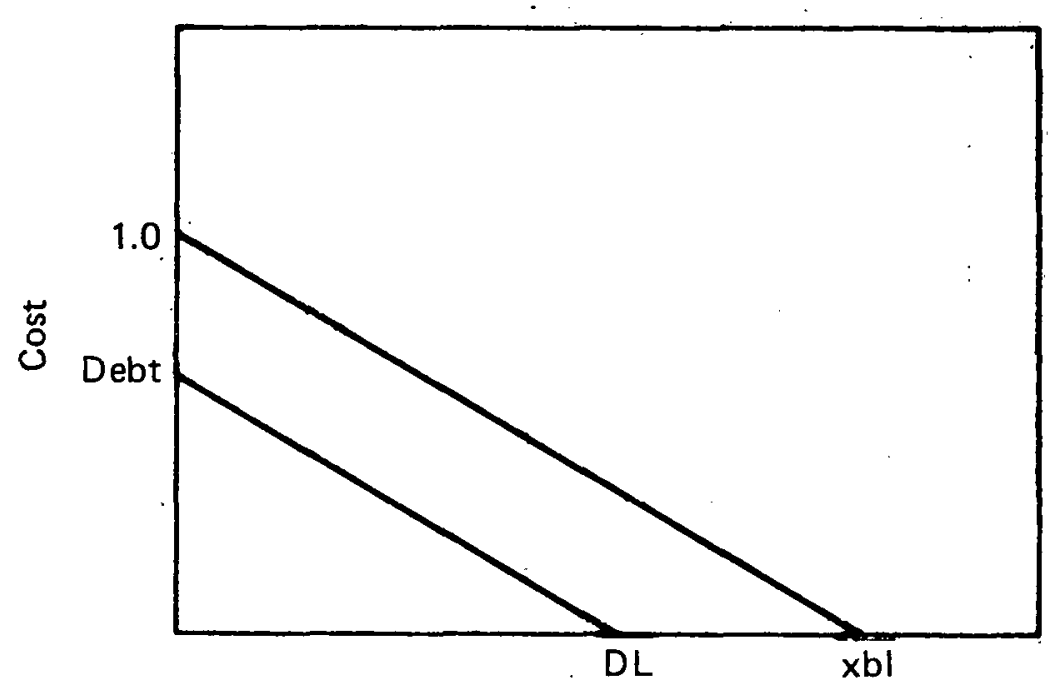

FIG. 3. Plant value and debt.

Time 
Therefore,

$$
\mathrm{EQF}=1-\frac{\mathrm{debt} \cdot \mathrm{DL}}{2} / \frac{\mathrm{xbl}}{2}
$$

or the initial debt for each monetary unit of plant investment is

$$
\text { debt }=(1-E Q F) \cdot \frac{x b l}{D L}
$$

It is now assumed that the borrowed money is required for a specified fraction of the plant construction time. Interest payments on this money are assumed to be fully deductible, in the sense that the investor has adequate income to take full advantage of the deductions. The following quantities are needed in the determination of the present value of debt:

a. INDEL - the real interest rate.

b. TCNSTR - the plant construction time.

c. FCCR - the fraction of construction time for which borrowed money is needed.

d. $\operatorname{disc}(n)-$ equal to disdel $+\operatorname{Xinfl}(n)$, the real discount rate plus the future effective inflation rate which is perceived at the present time (that is, in period $n$ ).

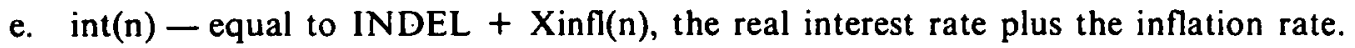

In the NPVDCF calculation, it is assumed that the money is borrowed all at once at time -FCCR - TCNSTR. The principal is repaid continuously, from time zero until time DL (debt life). Interest payments start at the time of borrowing.

The total payment at each time, including tax write-offs, is

$$
\begin{aligned}
\text { payment }= & \text { principal payment }+ \text { debt } \cdot \text { interest rate } \\
& -(\text { tax credit }=\text { debt } \cdot \text { interest rate } \cdot \text { tax rate }) .
\end{aligned}
$$

The continuous principal repayment rate $=\operatorname{debt} / \mathrm{DL}$, so

$$
\text { payment }=\left\{\begin{array}{cl}
0+(1-\mathrm{Taxr}) \cdot \mathrm{debt} \cdot \text { interest rate } & , \mathrm{t} \leqslant 0 . \\
\frac{\mathrm{debt}}{\mathrm{DL}}+\operatorname{debt}\left(1-\frac{t}{\mathrm{DL}}\right) \cdot \text { interest rate } \cdot(1-\text { Taxr }) & , \mathrm{t}>0 .
\end{array}\right.
$$

After time $t$, an amount debt $\cdot t / D L$ has been repaid. Note, again, that $t=0$ is actually period $n$, the construction time.

The absolute amount of the debt base is determined at the borrowing time. However, at some future time, $t$, the existing debt is in inflated dollars. To return that future debt to constant dollars, the factor $\mathrm{e}^{-\mathrm{Xinf} f(n)}$ is used; discounting is accomplished with the factor $\mathrm{e}^{- \text {disdel }}$. Thus, the factor $\mathrm{e}^{-\mathrm{disc}(n)}$ in the following expressions accomplishes both the necessary discounting and unfolding of inflation effects. 
Thus, noting that "payment" represents a cash outflow, we have

$$
\begin{aligned}
\operatorname{pvdebt}(n) & =\int_{- \text {TCNSTR } \cdot \text { FCCR }}^{0}(1-\text { Taxr }) \cdot \operatorname{debt} \cdot \operatorname{int}(n) \cdot e^{-d i s c(n) \cdot t} d t \\
& -\int_{0}^{D L}\left\{\left(\frac{\text { debt }}{\bar{D} \bar{L}}\right)+(1-\text { Taxr }) \cdot d e b t \cdot\left(1-\frac{t}{D L}\right) \cdot \operatorname{int}(n)\right\} e^{-d i s c(n) \cdot t} d t .
\end{aligned}
$$

The reader can easily verify that this expression yields

$$
\begin{aligned}
& \operatorname{pvdebt}(n)=\operatorname{debt} \frac{[(1-\operatorname{Taxr}) \operatorname{int}(n)-\operatorname{disc}(n)]\left(1-\mathrm{e}^{-\operatorname{disc}(n) \cdot D L}\right)}{[\operatorname{disc}(n)]^{2} D L} \\
&-\frac{(1-\operatorname{Taxr}) \operatorname{int}(n) e^{\operatorname{disc}(n) \cdot \operatorname{FCCR} \cdot \operatorname{TCNSTR}}}{\operatorname{disc}(n)} .
\end{aligned}
$$

2. Present Value of Equity. Recalling that we are considering plants which cost one monetary unit, the equity is $(1-\mathrm{debt})$. Discounting equity to time zero and adjusting for inflation gives

$$
\operatorname{pveqty}(n)=(\operatorname{debt}-1) \mathrm{e}^{\mathrm{disc}(\mathrm{n}) \cdot \mathrm{FCCR} \cdot \operatorname{TCNSTR}}
$$

(The negative value of pveqty represents a cash outflow.)

3. Present Value of Depreciation Tax Credit. This tax write-off represents a cash inflow for the investor. The amount of tax write-off is tied to the construction time investment and, thus, the absolute amount of deduction is subject to inflation effects. Double-declining-balance depreciation is used so that the tax credit in the interval $\mathrm{d} \tau_{-}$at time $\tau, \mathrm{S}(\tau)$ is

$$
\mathrm{S}(\tau)=\mathrm{tb}(\tau) \cdot \frac{2}{T L} \cdot \operatorname{Taxr} \cdot \mathrm{d} \tau
$$

where $\operatorname{tb}(\tau)$ is the tax base at time $\tau$.

An expression for $\mathrm{tb}(\tau)$ is easily derived:

$$
\begin{aligned}
& \mathrm{d}[\mathrm{tb}(\tau)]=-\mathrm{tb}(\tau) \cdot \frac{2}{\mathrm{TL}} \cdot \mathrm{dt}, \text { so } \\
& \ln \frac{\mathrm{tb}(\tau)}{\mathrm{tb}(0)}=-\left(\frac{2}{\mathrm{TL}}\right) \tau \quad \text { or, remembering that } \mathrm{tb}(0)=1 \\
& \operatorname{tb}(\tau)=\mathrm{e}^{-(2 / \mathrm{TL}) \tau} .
\end{aligned}
$$


Then

$\mathrm{S}(\tau)=\frac{2}{\mathrm{TL}} \cdot \operatorname{Taxr} \cdot \mathrm{e}^{-(2 / \mathrm{TL}) \tau} \mathrm{d} \tau$

The discount and inflation factor to get the NPV at time zero is $\mathrm{e}^{-\operatorname{disc}(n) \cdot \tau}$, so

$\operatorname{pvdp}=\frac{2 \cdot \operatorname{Taxr}}{\mathrm{TL}} \int_{0}^{\mathrm{TL}} \mathrm{e}^{-(\operatorname{disc}(\mathrm{n})+2 / \mathrm{TL}) \tau} \mathrm{d} \tau$

Extending the upper limit to infinity introduces only a small error, typically in the order of a few percent. Doing so yields the following value for the tax credit:

$$
\operatorname{pvdp}(n)=\frac{2 \cdot \operatorname{Taxr}}{[2+\operatorname{disc}(n) \cdot T L]}
$$

4. Present Value of Real Estate Taxes and Insurance. RTI is the effective real estate tax and insurance rate. The value at time $t$ of $R T I$ is $R T I$ - plant value.

Assuming a linear decrease in the (unit) plant value,

$$
\text { plant value }(t)=1-\frac{t}{x b l} \cdot e^{X i n f l(n) \cdot t}
$$

The exponential factor accounts for inflation effects. This is an example of the care required in handling inflation. The value of debt, equity, and depreciation were based on the real costs at the time of plant construction; presumably, the actual value of a plant will escalate at least with the inflation rate.

Discounting the plant value to zero time, and recalling that this is a cash outflow,

$$
\text { pvrti }=-\int_{0}^{x b \bar{l}} R T I \cdot\left(1-\frac{t}{x b l}\right) \cdot e^{x i n n(n) \cdot t} \cdot e^{-d i s c(n) \cdot t} \cdot d t
$$

Since $\operatorname{disc}(n)=\operatorname{Xinfl}(n)+$ disdel, this yields

$$
\operatorname{pvrti(n)}=\operatorname{RTI} \frac{\frac{1-\mathrm{e}^{-\mathrm{xbl} \mathrm{disdel}}}{\mathrm{xbl} \text { disdel }}-1}{\text { disdel }}
$$

5. Investment Tax Credit-XITC. The investment tax credit, XITC, is a one-time cash inflow which occurs at what I have termed time zero, namely, the construction period, $n$.

6. Price-Correction Factors. Before gathering the terms derived above into an expression for the present value of fixed costs, pvfix, two price-correction factors will be introduced. These are shutdown-expansion factor and secondary-materials factor. 
a. Shutdown-Expansion Factor-shexp(n)

- The shutdown-expansion factor attempts to adjust prices in response to either rapidly expanding demands or to the existence of an overcapacity. The response to increased demand, as evidenced by $\operatorname{con}(n)>0$, is increased prices; if $\operatorname{cap}(n)>$ Qout(n), an overcapacity exists and prices will be reduced. The correction is in the form of a multiplicative factor, shexp(n), applied to the expression for $\operatorname{pvfix}(n)$. Many reasonable expressions for shexp(n) can be envisioned. The expression currently implemented in EMS is

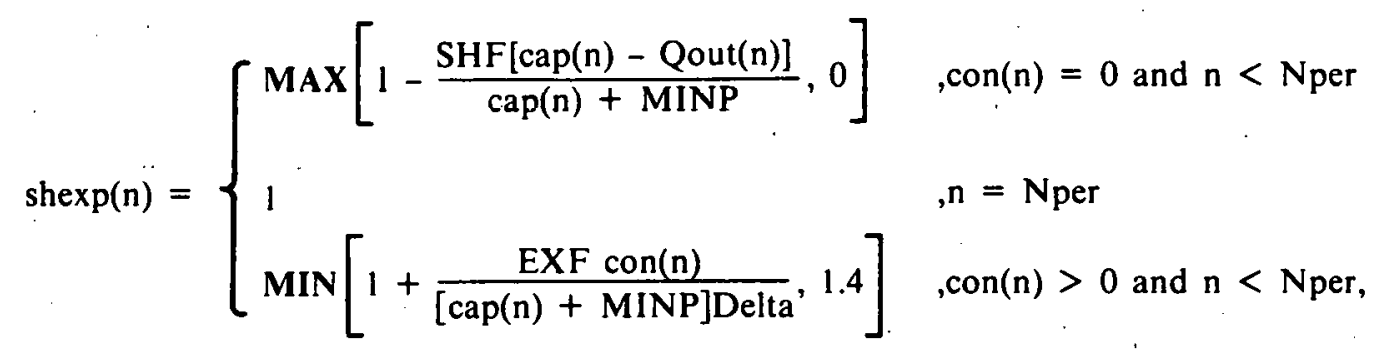

where

MINP = a "minimum industrv capacity," which reduces price effects when capacity is very small, such as for the first few plants of a new technology,

SHF = shutdown parameter,

EXF = expansion parameter.

b. Secondary-Materials Factor-smfact(n)

This factor simulates the effect on construction prices due to the need for secondary materials, such as pressure vessels, exploration equipment and railroad cars. If a large demand suddenly appeared, due to rapid expansion of plants needing a particular secondary material, shortages and higher prices for that material would be expected. A surplus of the secondary material might be expected to reduce construction costs, because that material would be available at a reduced price.

Secondary materials are handled as follows:

(1) A quantity of secondary materials is placed on the secondary input arc for the process under consideration. The quantity is given by

$\mathrm{Q}_{\mathrm{sec}}(\mathrm{i}, \mathrm{n})=\operatorname{con}(\mathrm{n}) \cdot \mathrm{SF}(\mathrm{i}) \cdot \mathrm{SCC} \cdot \operatorname{clearn}(\mathrm{n}) \cdot \operatorname{caf}$,

where

$S F(i)=$ fraction of capital cost from secondary material $i$, clearn(n) $=$ technological learning on construction costs.

The value of clearn is given by

Clearn $(n)= \begin{cases}1+\text { PRM }[\text { YRAVL }-\operatorname{Time}(n)] & \text { Time }(n) \leqslant \text { YRAVL } \\ (1-\operatorname{TCLC}) e^{-\operatorname{TCRC}[\operatorname{Time}(n)-\text { YRAVL }]+\operatorname{TCLC}} & , \operatorname{Time}(n)>\text { YRAVL },\end{cases}$ 
where

TCLC = capital cost technological change limit,

TCRC = capital cost technological change rate,

PRM = per year penalty for early availability.

The terms SCC and caf have been defined previously. Note that Qsec(i,n) is given in monetary units (to construct the plant capacity in question).

(2) $Q \sec (i, n)$ is summed over all processes in the network to get a total demand for "this type" of secondary material.

(3) This total secondary-material demand is passed to the secondary materials submodel, which returns a price of secondary materials, $\operatorname{Psec}(i, n)$. This price is based on a comparison of actual total demand for the material and an estimate made of its availability. Psec(i,n) is scaled with respect to 1.0 for nominal availability.

(4) If $\operatorname{SF}(i, n)$ is the fraction of the cost due to secondary material i, then $[1-\operatorname{SF}(i, n)]$ is the part of the cost due to the "main" industry. Remembering that we are calculating a cost per unit plant investment,

capital cost $=\Sigma \mathrm{Psec}(\mathrm{i}, \mathrm{n}) \cdot \mathrm{SF}(\mathrm{i})+[1-\Sigma \mathrm{SF}(\mathrm{i})] \cdot 1.0$,

and the correction factor is

$\operatorname{smfact}(n)=1+\Sigma(\operatorname{Psec}(i, n)-1) \cdot S F(i)$.

We are now reády to form an expression for pvfix(n):

$\operatorname{pvfix}(n)=\operatorname{SCC} \cdot \operatorname{caf} \cdot \operatorname{smfact}(n) \cdot \operatorname{shexp}(n) \cdot \operatorname{clearn}(n)$

$$
\cdot[\operatorname{pvdebt}(n)+\operatorname{pveqty}(n)+\operatorname{pvdp}(n)+\operatorname{pvrti}(n)+X I T C] .
$$

The term in brackets is the net present value at plant construction time, $n$, of a unit of monetary plant investment. SCC $\cdot \operatorname{clearn}(n)$ is the specific capital construction cost of bringing the plant on-line in period $n$. Changes in these costs as a function of time are embodied in clearn(n). Therefore, pvfix(n), the fixed cost per unit plant output is given in the same kind of (constant) dollars as is SCC.

Before leaving this section, it is appropriate to discuss Eq. (21) and the meaning of YRAVL, the year of technology availability. For times later than YRAVL, clearn is a usual exponential learning curve; before YRAVL, a price penalty is imposed, in the form of a multiplicative factor on SCC. Thus, plants can appear before YRAVL, provided they are competitive, even with the price penalty. YRAVL is, therefore, the year in which plants can be built and produce the product at a nominal, as opposed to premium, price. The idea here is that the process can be made available earlier than normal by extra and extreme expenditures in development and construction costs. These extraordinary costs result in higher selling prices for the process output. An exponential penalty trajectory is probably more appropriate than a linear one for reflecting this philosophy: Note also that learning starts at YRAVL irrespective of whether any of the plants using the process are actually "built" by the model at or before time YRAVL. An algorithm which starts learning when representative plants are actually constructed is under development.

We now move to a consideration of variable costs and the derivation of pvo(n). 
All the expressions developed so far have been the same for both SIMPLE and LSIMPLE. This will not be true for the variable costs. In order to avoid excessive text, multi-indexed variables representing the variable costs will be introduced and the values of the indices assigned when the differences between SIMPLE and LSIMPLE are explained.

7. Fuel Costs-fule(t,n). Fuel costs are based on the prices passed up the network. For $t=1$ ( $t$ is the index which will assign the variable to ejther SIMPLE or LSIMPLE):

$$
\text { fule }(1, n)=\sum_{i} \frac{\text { Pin }(i, n)}{\operatorname{EFF}(i) \cdot \text { elearn(n) }}
$$

The value of fule $(1, n)$ is just the sum of the efficiency-weighted prices of the input fuels, where the efficiencies are adjusted for possible learning.

The expression for fule $(2, n)$ is more complicated. EMS attempts to simulate a government-allocation process in which various producers "see" resulting higher fuel prices to a different degree depending on their relative priorities.

Recall that the presence of controls results in shadow prices, Lin and Lout, upon which decisions will be made. Lin is also, potentially, the price a producer may have to pay for the fuel in question. Define a fuel cost element as

$$
f c e(i, n)= \begin{cases}{[1-\operatorname{SPP}(i)] \operatorname{Pin}(i, n)+\operatorname{Lin}(i, n)} & , \operatorname{Lin}(i, n) \text { exists and } \operatorname{Lin}(i, n)>S P P(n) P i n(i, n) \\ \operatorname{Pin}(i, n) & , \operatorname{Lin}(i, n) \text { does not exist or } \\ & 0<\operatorname{Lin}(i, n) \leqslant S P P(n) P i n(i, n) \\ \operatorname{Pin}(i, n)+\operatorname{Lin}(i, n) & , \operatorname{Lin}(i, n) \text { exists and } \operatorname{Lin}(i, n) \leqslant 0,\end{cases}
$$

where $\operatorname{SPP}(i, n)=$ shadow price parameter (parameter).

If no shadow price is present, fce is equal to the input transaction price. The producer also pays the transaction price so long as the value of SPP is such that Lin $\leqslant$ SPP - Pin. As soon as Lin $>$ SPP - Pin, the fuel-cost element for a given producer begins to reflect the presence of the shadow price, Lin, to a degree determined by the magnitude of SPP. The value of fule $(2, n)$ is then defined as

$$
\text { fule }(2, n)=\sum_{i} \frac{f c e(i, n)}{\operatorname{Err(i)} \cdot \text { elearn(n) }}
$$

It should be noted that the prices being used to determine fule are constant dollars of the same type as SCC.

\section{Operating and Maintenance Costs-omle(n).}

$$
\text { umle(n) }- \text { OM } \cdot \text { ulean }(11)+\text { VPN , }
$$

where

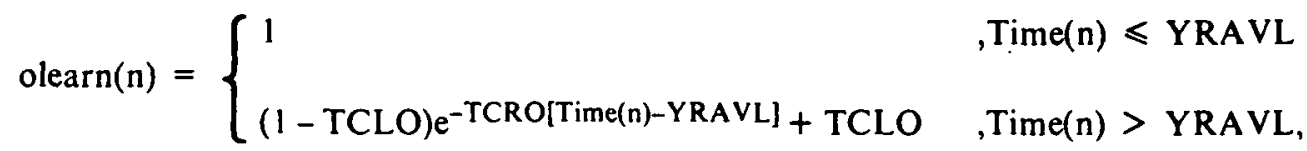


where TCLO $=$ the technological change limit for operating (parameter) and TCRO $=$ the technology change rate for operating (parameter).

The units of omle(n) should be constant dollars of the same type as SCC.

9. Operating Income-Income(n). The last variable cost is the net operating income, which is equal to the selling price less the expenses of operating and fuel costs. Once again it will be necessary to introduce an indexed variable to continue the unified treatment of SIMPLE and LSIMPLE. Define

$$
R(t, n)= \begin{cases}\text { Pout }(n) & , t=1 \\ \text { Lout }(n) & , t=2\end{cases}
$$

In performing the NPVDCF calculation for prices in period $n$, it is necessary to assign values for the income in periods later in time. Denote those incomes as $I(m>n)$. We will defer the question of how $I(m>n)$ is determined for the moment and continue the development of an expression for the net present value in period $\mathrm{n}$ of these future incomes.

First, I(n), the income in the present period, is

$$
I(n)=R(t, n)-\text { omle }(n)-\text { fule }(t, n)
$$

The actual discounting is complicated somewhat by the assumption of constant prices over a time Delta centered at Time(n). I(n) is considered to be effective for half a period, from construction time Time(n) to Time $(n)+0.5 \cdot$ Delta. $I(n+i b l)$, the income in the period leading up to the time of plant wear-out, is effective from Time $(n+i b l)-0.5 \cdot$ Delta to Time $(n+i b l)$, and $I(n<m<i b l)$ is effective from time Time $(m)-0.5$ - Delta to Time $(\mathrm{m})+0.5$ Delta. Therefore:

a. I(n) discounts to period $n$ with

$\mathrm{I}(\mathrm{n}) \int_{0}^{0.5 \cdot \text { Delta }} \mathrm{e}^{-\mathrm{disdel} \cdot \mathrm{t}} \cdot \mathrm{dt}=\mathrm{I}(\mathrm{n}) \cdot \mathrm{gl}$.

b. $\quad \mathbf{I}(\mathrm{n}<\mathrm{m}<\mathrm{ibl})$ discounts to period $\mathrm{n}$ with

$$
\begin{aligned}
& \mathrm{I}(\mathrm{m}) \cdot \mathrm{e}^{-\mathrm{disdel} \cdot(\mathrm{m}-\mathrm{n})} \int_{-0.5 \cdot \text { Delta }}^{0} \mathrm{e}^{-\mathrm{disdel} \cdot \mathrm{t}} \mathrm{dt}+\int_{0}^{-0.5 \cdot \text { Delta }} \mathrm{e}^{-\mathrm{disdel} \cdot \mathrm{t}} \mathrm{dt}, \\
& \text { or } \mathrm{I}(\mathrm{m}) \cdot \mathrm{g} \mathrm{O}^{(\mathrm{m}-\mathrm{n})} \cdot \mathrm{g} .
\end{aligned}
$$

c. I(ibl) discounts to period $\mathrm{n}$ with

$$
\begin{aligned}
& I(\mathrm{ibl}) \cdot \mathrm{e}^{-\mathrm{disdel} \cdot(\mathrm{ibl})} \int_{-0.5 \cdot \text { Delta }}^{0} \mathrm{e}^{-\mathrm{disdel} \cdot \mathrm{t}} \mathrm{dt}, \\
& \text { or } \mathrm{I}(\mathrm{ibl}) \cdot \mathrm{g} 0^{\mathrm{ibl}} \cdot \mathrm{g}^{2}
\end{aligned}
$$


where

$$
\begin{aligned}
& \mathrm{g} 0=\mathrm{e}^{- \text {disdel Delta }} \\
& \mathrm{g} 1=\frac{1-\mathrm{e}^{0.5 \text { disdel Delta }}}{\text { disdel }}, \\
& \mathrm{g} 2=\frac{\mathrm{e}^{0.5 \text { disdel Delta }}-1}{\text { disdel }}, \\
& \mathrm{g}=\mathrm{g} 1+\mathrm{g} 2,
\end{aligned}
$$

It should be noted that discounting is done with disdel, the real discount rate. Since all variable costs have been given in constant (SCC type) dollars, no compensation for inflation is necessary.

Remembering that income is taxed at a rate Taxr, and using Eq. (29), pvo(n) is the present value of future incomes, we obtain

$$
\operatorname{pvo}(n) /(1-T a x r)=g l \cdot[R(t, n)-o m l e(n)-f u l e(t, n)]+g \sum_{j=1}^{i b l-1} g 0^{j} 1(n+j)+g 2 \cdot g 0^{i b l} \cdot I(i b l)
$$

We can go no further until values for $\mathrm{I}(\mathrm{m}>\mathrm{n})$ have been assigned. Once this has been done, Eqs. (23) and (37) are substituted into the basic NPVDCF expression,

$$
\operatorname{pvfix}(n)+\operatorname{pvo}(n)=0,
$$

and solved for the period-n prices $R(t, n)$.

$I(m>n)$ are the prices the developer perceives will be effective in the future. As they are integral to the calculation of current price, it would be expected that the resulting prices might be highly dependent on the methodology used to model the developer's perceptions (also termed foresight). The reader is referred to Ref. 1, which considers this issue in detail. The remainder of this section is based on the EMS standard foresight-modeling scheme.

EMS first calculates the output prices at the time horizon, that is, at $\mathrm{n}=\mathrm{Nper}$. A constant income, $\mathrm{d}$, is assumed for $\mathrm{xbl}$ years. At $\mathrm{n}=\mathrm{Nper}$,

$$
\operatorname{pvo}(\text { Nper }) /(1-\text { Taxr })=d \int_{-x b l}^{0} e^{d i s d e l \cdot t} d t=\frac{d}{d i s d e l}\left(1-g 0^{i b l}\right)
$$

By setting pvo(Nper) = -pvfix(Nper) and using Eq. (29), we obtain as the horizon prices:

$$
R(t, N p e r)=\frac{-p v f i x(N p e r) \cdot \text { disdel }}{\left(1-g 0^{i b l}\right) \cdot(1-\text { Taxr })}+\text { omle }(\text { Nper })+\text { fule }(t, N \text { per })
$$


EMS now moves backward in time and bases the perceived future incomes on the actual (known) calculated future incomes. In particular, if $\operatorname{lact}(m>n)$ is the already calculated future income for a period $m$ (later than the current period $\mathrm{n}$ ), then

$$
\operatorname{Iact}(m)=R(t, m)-\text { omle }(m)-\text { fule }(t, m) \quad .^{*}
$$

EMS assigns the perceived future income as a combination of actual (known) future income, lact and the current (unknown) income, $I$,

$$
I(n)=h \cdot I(n)+(1-h) \cdot \operatorname{Iact}(m),
$$

where

$$
\mathbf{h}=\mathrm{e}^{- \text {SMOOTH} \cdot \text { Delta }} \text {. }
$$

SMOOTH is the user-specified foresight-mixing parameter. If SMOOTH is small, future prices are perceived to be equal to present prices and the developer is said to be myopic. If SMOOTH is large, future perceived prices are the actual calculated future prices and the developer is considered to be clairvoyant. Intermediate values of SMOOTH give the developer "fuzzy" foresight.

Insertion of Eq. (40) into Eq. (37) and elimination of Iact(m) from the resulting equation by using Eq. (39) yield an expression which can be solved for $R(t, n)$ in terms of known and previously calculated quantities. The algebra to get $R(t, n)$ is straightforward and is not presented here; the result is:

$\mathbf{R}(\mathbf{t}, \mathbf{n})$

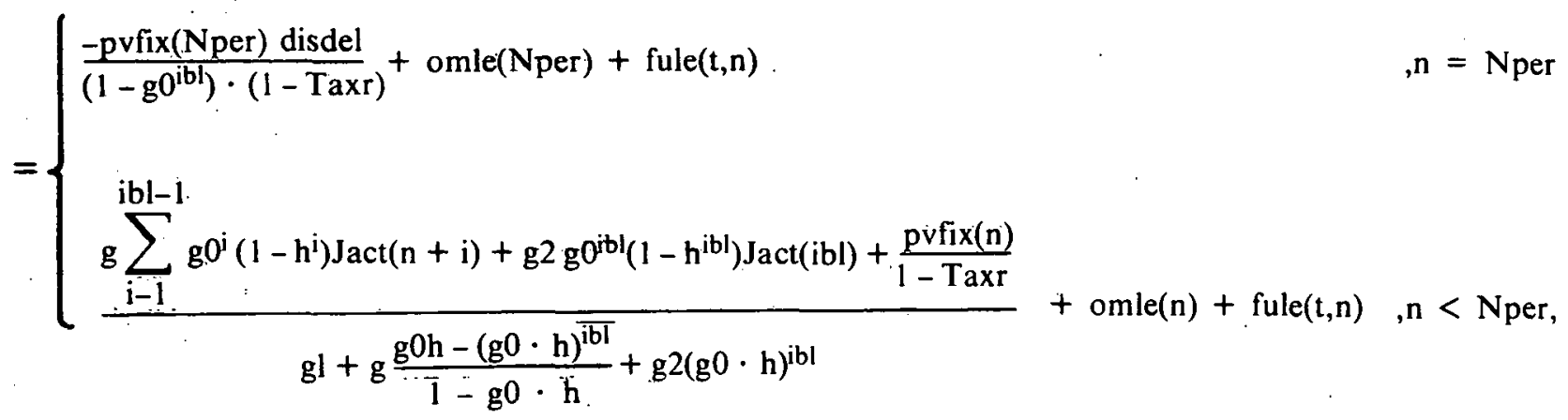

where $\operatorname{Jact}(n)=\operatorname{Iact}(n) \cdot \operatorname{capcr}(n)$ and $\operatorname{capcr}(n)=\operatorname{Qout}(n) / \operatorname{cap}(n)$.

\footnotetext{
- Iact(n) is the same abstract quantity as $I(n)$. I have changed $I(n)$ to lact(n) after the quantity has actually been calculated, in order to indicate which variables are known and which are, as yet, unknown.
} 
There are three points which now need to be considered.

(1) The correction factor capcr( $n$ ) appears because the equations were derived assuming a full unit plant output. If the full capacity of existing plants is not used, the net income over all plants is reduced by the ratio Qout(n)/cap(n). (In this regard, recall the discussion concerning possible inaccuracies in the value of $\operatorname{cap}(\mathrm{n})$ which result from the plant vintaging algorithm.)

(2) The summation from $\mathrm{j}=1$ to ibl in Eq. (37) could reach time periods beyond Nper, the problem's last period. In that case, the index $m$ in Eq. (39) would exceed Nper also. If this happens, Iact $(m>$ Nper) is calculated with the assumption that $R(t, m>N p e r)=R(t, N p e r)$, omle $(m>N$ per $)=$ omle $(N p e r)$, and fule $(t, m>N p e r)$ is the same as fule(t,Nper), except that the learning factor elearn(m) would be that at the actual value of Time(m).

(3) The last point which requires consideration is the difference between SIMPLE and LSIMPLE:

(a) LSIMPLE uses input shadow prices (if they exist) to calculate output shadow prices and input transaction prices to calculate output transaction prices. Setting $t=1$ and $t=2$ on both sides of Eq. (41) yields two equations, the first for transaction prices, the second for shadow prices.

(b) SIMPLE uses input shadow prices (if they exist) to calculate output transaction prices. No output shadow prices are produced. The equation for the output price Pout(n) is derived from Eq. (41) by setting $t=1$ in $R(t, n)$ and $t=2$ in fule $(t, n)$.

Before concluding the discussion of the submodels SIMPLE and LSIMPLE, I would like to be sure that the reader clearly understands the implications of the algorithm. The price derived in a period $\mathrm{n}$ is that for output from plants built in that period. Plants of the same type built at earlier times, which still exist in period $\mathrm{n}$, are assumed to change their price to the period-n price starting in period $\mathrm{n}$. That is, a long-term competitive equilibrium at the period-n marginal price is assumed to take place in period $n$. (Monopolistic or oligopolistic practices can be modeled in EMS, but not with submodel SIMPLE.) This type of pricing is appropriate for many unregulated industries. For regulated industries, such as the electric utilities, the prices derived must be interpreted as the marginal price of new facilities. (Average pricing can, with great difficulty, be accomplished in EMS, but not directly with SIMPLE.)

\section{TRANS AND LTRANS}

TRANS and LTRANS are the submodels used to describe transportation processes. They differ from SIMPLE and LSIMPLE only in the inclusion of the distance the energy form is transported as a factor in calculating input quantities and output prices.

Primary energy type 1 [that is, Qin $(1, n)$ ] is considered to be the energy form that is actually transported (gas in a gas pipe, coal in a unit train, etc.). Primary energy types 2 through 5 , as is appropriate, are considered to be used in moving the energy type 1 . For example, energy type 1 might be crude oil and energy type 2 might be electricity required to run pumps on the oil pipeline.

The distance through which energy type 1 is moved is specified by the user as the parameter DISTANCE. Then define

$$
\mathrm{d}=\text { DISTANCE } / 1000 \text {. }
$$

TRANS (LTRANS) uses values for the specific capital cost (denoted SCC') and operating and maintenance cost (denoted $\mathrm{OM}^{\prime}$ ) given by

$$
\begin{aligned}
\mathrm{SCC}^{\prime} & =\mathrm{SCC} \cdot \mathrm{d} \\
\mathrm{OM}^{\prime} & =\mathrm{OM} \cdot \mathrm{d},
\end{aligned}
$$


where

SCC = specific capital costs as defined for SIMPLE,

$\mathrm{OM}=$ operating and maintenance costs as defined for SIMPLE.

That is, SCC and OM should be given for 1000 miles of transportation.

The efficiency for energy type 1 is also to be given for 1000 miles. In this case, the efficiency should reflect losses or uses of the fuel being transported, such as leaks from pipelines or use of gas to fuel pumps. The efficiency actually used in the calculations, $\operatorname{EFF}(1)^{\prime}$, is

$$
\operatorname{EFF}(1)^{\prime}=\operatorname{EFF}(1)^{d}
$$

Expressions for $\operatorname{EFF}(\mathrm{i}>1)$ are derived under the assumption that the use of an energy type $\mathrm{i}>1$ will compensate for the need to use energy type 1 in the transportation process. If energy type 1 were used, we would expect the amount of that energy after a distance of transportation, $x$, to follow an exponential decay law,

$$
Q(1, x)=Q(1,0) e^{-\lambda x}
$$

The total amount of energy type 1 transmitted a distance $L$ is obtained by integrating this expression

$$
Q(1, L)=Q(1,0)\left(\frac{1-e^{-\lambda L}}{\lambda}\right)
$$

We assume that the amount of energy used to move the energy, $\mathrm{QU}(\mathrm{x})$, is proportional to the amount moved; then

$$
\frac{\mathrm{QU}(\mathrm{L})}{\mathrm{Q}(1,0)}=\left(\frac{1-\mathrm{e}^{-\lambda \mathrm{L}}}{1-\mathrm{e}^{-\lambda}}\right) \frac{\mathrm{QU}(1)}{\mathrm{Q}(1,0)}
$$

Now, if the primary energy (type 1) were used to move itself

$$
\mathrm{Q}(1, \mathrm{~L})=\mathrm{e}^{-\lambda \mathrm{L}} \mathrm{Q}(1,0)=\mathrm{Q}(1,0) \operatorname{EFF}(1)^{\mathrm{L}}
$$

If energies of type $\mathrm{i}>1$ are used instead of using some of $Q(1)$, then $Q(i>2)=Q U$ and, by definition, $\mathrm{QU}(\mathrm{L}) / \mathrm{Q}(1,0)=\mathrm{Q}(\mathrm{i}>1) / \mathrm{Q}(1,0)=\operatorname{EFF}(\mathrm{i}>1)$. Thus,

$$
\operatorname{EFF}(i>1, L)=\left(\frac{1-\operatorname{EFF}(1)^{L}}{1-\operatorname{EFF}(1)}\right) \cdot \operatorname{EFF}(i>1,1)
$$

All that remains is to observe that unit length really means 1000 miles so that $\mathrm{L}=\mathrm{d}$, and to normalize the expression to unit output of type-1 energy by dividing by EFF(1)L. [Note that (Eq. 45) is not normalized.] Using Eq. (44), we get 


$$
E F F^{\prime}(i)= \begin{cases}E F F(1)^{d} & , i=1 \\ \frac{1-E F F^{\prime}(1)}{E F F^{\prime}(1)[1-E F F(1)]} E F F(i) & , 1>1 .\end{cases}
$$

All the SIMPLE (LSIMPLE) calculations now proceed as before, with the use of SCC', OM', and EFF'(i), instead of SCC, OM, and EFF(i).

\section{TRIVIAL AND LTRIVIAL}

TRIVIAL and LTRIVIAL are conversion submodels in which the complications due to capital costs, construction, vintaging, etc., are not present or are included in operating and maintenance costs. Like SIMPLE, TRIVIAL and LTRIVIAL allow up to five primary and five secondary input energy types; a single output energy type results. The data inputs to TRIVIAL (LTRIVIAL) are:

1. OM-Operating and Maintenance costs.

2. olearn(n)-Learning on OM.

3. VPN-Variable penalty.

4. fulc(n)-Input fucl prices.

5. Early arrival penalties.

The outputs are:

1. Output prices.

2. Input quantities.

Like SIMPLE and LSIMPLE, TRIVIAL and LTRIVIAL differ only in the treatment of transaction and shadow prices. Therefore, a unified discussion of the two submodels is presented.

\section{Quantity Calculation}

$$
\operatorname{Qin}(\mathrm{i}, \mathrm{n})=\operatorname{Qout}(\mathrm{n}) / \operatorname{EFF}(\mathrm{i})
$$

Improvements in efficiency over time are not allowed.

\section{Price Calculation}

Define the fuel costs per unit output as

$$
\text { fule }(t, n)= \begin{cases}\sum_{i} \frac{\operatorname{Pin}(i, n)}{\operatorname{EFF}(i)} & , t=1 \\ \sum_{i} \frac{f c e(i, n)}{\operatorname{EFF}(i)} & , t=2,\end{cases}
$$

* Equation numbers 47 through 52 are intentionally omitted. 
where fce $(i, n)$ is the same fuel cost element as defined in SIMPLE, Eq. (25). Here, fule $(t, n)$ is the same as that defined in Eqs. (24a) and (24b) for SIMPLE, but with no learning allowed. As was the case in SIMPLE, Eq. (28), define

$$
R(t, n)= \begin{cases}\text { Pout }(n) & , t=1 \\ \operatorname{Lout}(n) & , t=2 .\end{cases}
$$

Then

$$
R(t, n)= \begin{cases}\text { OM } \cdot \text { olearn }(n)+V P N+\text { fule }(t, n) & \text { Time }(n) \geqslant \text { YRAVL } \\ \text { OM } \cdot[1+\text { PRM } \cdot(\text { YRAVL }-\operatorname{Time}(n))] & \\ + \text { VPN }+ \text { fule }(t, n) & \text { Time }(n)<\text { YRAVL }\end{cases}
$$

LTRIVIAL uses input shadow prices, if they exist, to calculate output shadow prices and input transaction prices to determine output transaction prices. These two relations can be obtained from Eq. (55) by setting $\mathrm{t}=1$ and 2 on both sides. TRIVIAL uses input shadow prices, if they exist, to derive output transaction prices; no output shadow prices are present.

\section{RESOURCE, OLDRESOURCE, AND RESSL}

Submodel RESOURCE, and its variants OLDRESOURCE and RESSL, model the resourceproduction process. There are no primary-energy inputs to RESOURCE, but up to five secondary material inputs are allowed. RESOURCE conceptually "produces" whatever quantity of raw energy resources is required by the demands from the network above it. Raw resource prices have three components: the first is the cost of developing the resource, the second is the developer's return on investment, and the third is rent demanded by the resource owner.

Development costs and the developer's return on investment are calculated with a variation of the SIMPLE methodology. Resource owners are modeled as having a perceived set of future profit margins on which they base decisions related to the magnitudes of the rents they will demand. The rent in a given period is essentially the largest future profit margin, in a discounted sense, that the owner believes would be achievable. The owner is modeled as being willing to withhold development of any resources not salable at the set price, including the demanded rent.

How the profit margins perceived by the resource owner are assigned is important. The reader is referred to Ref. I for a more complete discussion of this topic. Currently, EMS bases the owner's future perceived profit margins on the actual calculated future profit margins. Perceived and calculated margins, however, are not necessarily equal.

\section{Price Calculation}

The first task is to account for development costs and then calculate a developer's selling price which reflects his or her expected return on investment. To this end, define

$$
\operatorname{pvfct}(n)=\operatorname{smfact}(n) \operatorname{clearn}(n),
$$


where

$\operatorname{smfact}(\mathrm{n})=$ secondary materials correction factor [SIMPLE, Eq. (22)] ,

$\operatorname{clearn}(n)=$ learning on construction costs [SIMPLE, Eq. (21)],

and

$\operatorname{pvfci}(n)=\operatorname{pvdebt}(n)+\operatorname{pveqty}(n)+\operatorname{pvdp}(n)+\operatorname{pvrti}(n)+X I T C$,

where

pvdebt(n) = present. value of debt [SIMPLE, Eq. (16)],

$\operatorname{pveqty}(n)=$ present value of equity [SIMPLE, Eq. (17)],

$\operatorname{pvdp}(n) \quad=$ present value of depreciation tax credit [SIMPLE, Eq. (18)],

pvrti(n) = present value of real estate taxes and insurance [SIMPLE, Eq. (19)],

XITC $\quad=$ investment tax credit.

An equation analogous to SIMPLE, Eq. (23) is written for the fixed costs in period $n$

$$
\operatorname{pvfix}(n) \quad=\operatorname{scc}(n) \cdot \operatorname{pvfct}(n) \cdot \operatorname{shexp}(n) \cdot \operatorname{pvfci}(n)
$$

It should be noted that the specific capital cost, $\operatorname{scc}(\mathbf{n})$, is time-dependent for the resource-production process. It is well known that developing a given energy-resource type generally becomes more expensive as the amount of resource already developed increases. This is true, at least, for non-renewable resources. Therefore, the model user must specify the specific capital cost, and also the operating and maintenance costs, as a function of cumulative committed capacity for resource production. This is done through the input arrays $S C C(k)$, $\mathrm{OM}(\mathrm{k})$ and $\mathrm{QTY}(\mathrm{k}) ; \mathrm{SCC}(\mathrm{k})$ and $\mathrm{OM}(\mathrm{k})$ are the specific capital costs and operating and maintenance costs at the cumulative committed capacity QTY $(k)$. (The maximum value of $k$ currently allowed is 6.)

For a cumulative committed capacity in period $n, q c(n)$, that period's specific capital cost, $\operatorname{scc}(n)$ [to be used in Eq. (58)], and value of operating and maintenance costs, om(n) (to be used later), are given by

$$
\begin{aligned}
& \operatorname{scc}(n)= \begin{cases}\operatorname{caf}\{\operatorname{SCC}(i-1) z(n)+\operatorname{SCC}(i)[1-z(n)]\} & , z(n) \text { is defined } \\
\operatorname{cafSCC}(i) & , i=1 \text { when } q c(n)<Q T Y(1) \text { and }\end{cases} \\
& \operatorname{om}(n)= \begin{cases}\operatorname{OM}(\mathrm{i}-1) z(n) \mid \operatorname{OM}(\mathrm{i})[1-z(n)] & , \mathrm{z}(\mathrm{n}) \text { is defined } \\
\mathrm{OM}(\mathrm{i}) & , \mathrm{i}=1 \text { when } \mathrm{qc}(\mathrm{n})<\mathrm{QTY}(1) \text { and } \\
& \mathrm{i}=6 \text { when } \mathrm{qc}(\mathrm{n}) \geqslant \mathrm{QTY}(6),\end{cases}
\end{aligned}
$$


where

$$
z(n)= \begin{cases}\frac{Q T Y(i)-q c(n)}{Q T Y(i)-Q T Y(i-1)} & , Q T Y(i-1)<q c(n) \leqslant Q T Y(i) \\ \text { Undefined } & , q c(n)<\operatorname{QTY}(1) \text { or } q c(n) \geqslant Q T Y(6)\end{cases}
$$

That is, $\operatorname{scc}(\mathrm{n})$ and $\mathrm{om}(\mathrm{n})$ are obtained by interpolation or extrapolation of the input arrays SCC and OM. Note the inclusion of the correction factor, caf [SIMPLE, Eq. (14)] in Eq. (59).

It is next necessary to develop an expression for $\mathrm{qc}(\mathrm{n})$. The analysis follows that for plant construction in SIMPLE, but with the complication that we must consider the possibility of committed resource not expended during times of overcapacity. If $h(n)$ denotes the unused capacity, then

$$
h(n)= \begin{cases}0 & , n=1 \\ \operatorname{MAX}[\operatorname{cap}(n-1)-\operatorname{Qout}(n)-w(n)+h(n-1), 0] & , n>1 .\end{cases}
$$

That is, the overcapacity is the difference between current demand and the sum of the last period capacity and last period overcapacity, less the wear-outs.* If this is positive, there is no overcapacity and $h(n)$ is set to zero.

The construction, con(n), is derived in the same way as for SIMPLE, Eq. (11), except that $h(n-1)$ must be included as part of the last-period capacity.

$$
\operatorname{con}(n)= \begin{cases}\frac{\text { Qout }(1)(r-1)^{i b i-1}}{r^{i b l-1}} & , n=1 \text { and } r \neq 1 \\ \frac{\text { Qout }(1)}{i b l} & , n=1 \text { and } r=1 \\ \text { MAX }[\text { Qout }(n)-\operatorname{cap}(n-1)+w(n)-h(n-1), 0] & , n>1 .\end{cases}
$$

The cumulative committed capacity is then defined by the recursive relation

$$
q c(n)=q c(n-1)+\frac{\text { con(n)iblDelta }}{\text { elearn(n)EFF }}
$$

Recall that con(n) represents the construction of a facility that will produce resources for ibl periods or ibl - Delta years, thus committing a resource in the amount con(n) $\cdot \mathrm{ibl} \cdot$ Delta. The denominator allows inclusion of production-efficiency effects.

There is the question of how qc should be initialized. The SCC and OM arrays are given as a function of cumulative committed capacity. Implied in this definition is some point in time at which resource dedication begins. That is, the expression "cumulative committed capacity" should be followed by the statement "since the year xxxx," where xxxx is some appropriate calendar year. There is currently some controversy over how the initialization of qc should be done. The expression traditionally used in EMS is

"In this case, "wear-outs" represents the amount of resource-production capacity that is no longer productive. 


$$
q c(1)= \begin{cases}\frac{\text { Qout }(1)\left[(i b l \cdot r-i b l-1) r^{\mathrm{ibl}}+1\right] \text { Delta }}{\left(\mathrm{r}^{\mathrm{b} l}-1\right)(\mathrm{r}-1) \text { elearn(1)EFF }} & , \mathrm{r} \neq 1 \\ \frac{\text { Qout }(1)}{2}(\mathrm{ibl}+1) \frac{\text { Delta }}{\text { EFFelearn(1) }} & , \mathrm{r}=1 .\end{cases}
$$

The derivation of this expression is given in Appendix A. Several other options for $q c(1)$ are also now available to the modeler.

At this point we could write an expression for the developer's output prices; it would be SIMPLE, Eq. (41), without the fule $(t, n)$ term (there are no primary energy inputs) and with $t=1$ in $R(t, n)$ so Pout(n) appears on the left side. We shall not do so, as an equation for the total resource price, including the rent, is desired. Once the total price is determined, it will turn out to be easy to extract the developer's price, if required.

The resource owner will charge rent if he/she believes that the difference between selling price and total development costs (including the developer's return on investment) will increase in the future. More precisely, the resource owner conceptually withholds the resource until a time at which other resource owners have "sold out" sufficiently to cause the resource selling price to increase. At that point the withholding owner could develop his/her resource at a lower cost.

To determine the rént to be charged, the resource owner examines the quantity

$$
\operatorname{rent}(n, m)=[\operatorname{Ppro}(m)-\operatorname{DCpro}(m)] \mathrm{e}^{-\operatorname{DRRO} \cdot \operatorname{DELTA} \cdot(m-n)}
$$

where

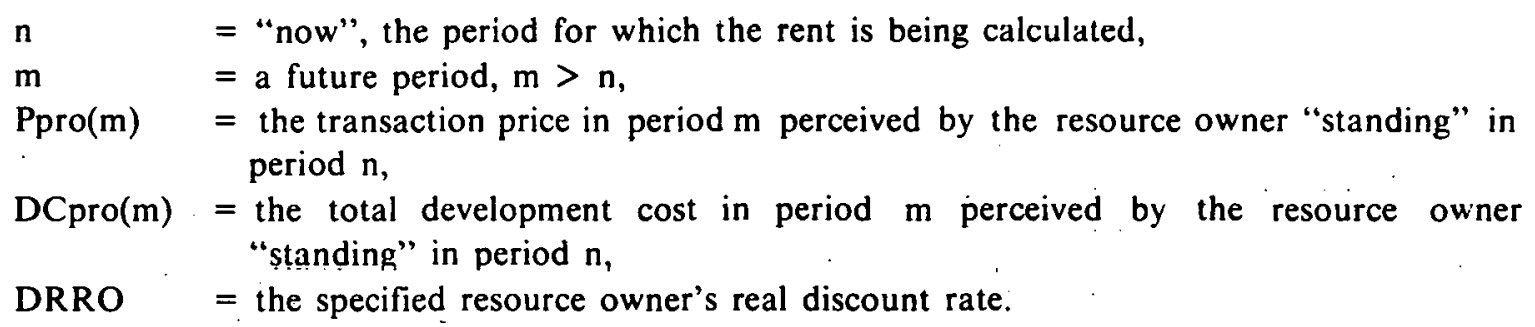

As defined in Eq. (65), rent $(n, m)$ is just the perceived profit margin discounted to the current time period. The rent which is ultimately charged is

$$
\operatorname{Rent}(n)=\underset{n}{\operatorname{Morz}}[\operatorname{rent}(n, m)],
$$

where horz is the problem horizon time period for the rent calculation. At the modeler's option, horz is either the last period being modeled, or from I to 60 periods beyond that last period. In the first case, rent is set to zero in the last period; in the second case, a price of substitutes must be specified and the value of horz results when the resource marginal development costs equal or exceed this price. 
This method of modeling the resource owner's rent determination is not without shortcomings, particularly for certain types of future price trajectories. However, it is beyond the scope of this report to pursue this issue further.

The essence of the rent and foresight calculation is determining the factor [Ppro $(m)-D C p r o(m)]$, and we can go no further until a methodology for doing so is chosen. The reader is referred to Ref. 1 for a more complete discussion of the ramifications of this methodology. The standard EMS algorithm bases the rent calculation on the actual calculated future price.

SIMPLE, Eq. (41), is the basis for the rent calculation. We will rewrite this equation in a form suitable for the present purposes:

1. $R(t, n)$ becomes the transaction price Pout(n).

2. As there are no fuel costs, fule $(t, n)$ is set to zero.

3. $\operatorname{pvfix}(n)$ will be written, for reasons which will become clear later, as

$$
\operatorname{pvfix}(n)=\operatorname{scc}(n) \cdot \operatorname{pvfci}(n) \cdot \operatorname{pvfct}(m) \cdot \operatorname{shexp}(m)
$$

4. Since $\operatorname{capcr}(n) \rightarrow 1.0, \operatorname{Jact}(k) \rightarrow \operatorname{Pout}(k)-$ omle(k), which, recognizing the time dependence of om, we shall write as

$$
\operatorname{Jact}(m)=\operatorname{Pout}(m)-\operatorname{om}(n) \cdot \operatorname{olearn}(m) .^{*}
$$

5. Set the difference between the left and right sides of Eq. (41) to pma(n,m).

To avoid some writing, set

$$
g 3=g 1+\frac{g 0 \cdot h-(g 0 h)^{i b l}}{1-g 0: h}+g 2(g 0 \cdot h)^{i b l}
$$

so the modified Eq. (41) becomes

$$
\operatorname{pma}(n, m)=[\operatorname{Pout}(m)-(\text { om }(n) \cdot \text { olearn }(m)] \cdot g 3
$$

$+g \sum_{i=1}^{i b l-1} g 0^{i}\left(1-h^{i}\right) \cdot[\operatorname{Pout}(m+i)-o m(n) \cdot \operatorname{olearn}(m+i)]$

$$
\begin{aligned}
+\mathrm{g} 2 \cdot g 0^{i b l}\left(1-h^{i b l}\right) & {[\operatorname{Pout}(m+i b l)-o m(n) \cdot \operatorname{olearn}(m+i b l)] } \\
& +\operatorname{scc}(n) \cdot \operatorname{pvfct}(m) \cdot \operatorname{pvfci}(n) \cdot \operatorname{shexp}(m) /(1-\operatorname{Taxr})
\end{aligned}
$$

*To save writing, the additive term VPN will not be carried through the development. It will be restored in the final expression. 
The interpretation of Eq. (68) is as follows: Eq. (41) simply splits the price in the period under consideration from the present value of the other variable costs and fixed charges. When we are trying to calculate Pout(k) for some period k, Eq. (4l) is an identity; Eq. (68) would lead to the same result if we put $m=n$ (and restored the fule term if needed). Then pma would be zero. However, we are modeling a resource owner who is comparing the future selling price to the future development costs under the assumption that he/she might withhold the resource until the future period $\mathrm{m}$. At that time, he/she assumes that the other resource owners have sold off their resources to a point at which the selling prices have increased. However, the withheld resource could be developed at the costs associated with the present time. Thus, period-n values for scc and om are used in Eq. (68), but with future period, $\mathrm{m}$, learning and secondary materials, and shutdown-expansion factors. Generally speaking, selling prices would be expected to increase more rapidly than development costs, and $p m a(n, m)$, the actual profit margin in period $m$ as seen from period $n$, will be positive. The resource owner will want to recover this potential future "windfall" (in a discounted sense) by increasing the present period-n prices, that is, by charging rent. If the resources are not salable at the set price, including rent, the resource owner simply waits for the higher future prices.

Equation (68) can be simplified somewhat by assigning all learning to be the value at the future period $\mathrm{m}$, in which case the terms involving om become

$$
\ldots-\operatorname{om}(n) \cdot \operatorname{olearn}(m) \cdot\left[g 3-g \Sigma_{g} 0^{i}\left(1-h^{i}\right)+g 2 g 0^{i b l}\left(1-h^{i b l}\right)\right]
$$

With a little manipulation of the geometric series in the brackets and of the definition of $\mathrm{g} 3$, itself the sum of a geometric series, Eq. (69) becomes

$$
\ldots-\operatorname{om}(\mathrm{n}) \cdot \operatorname{olearn}(\mathrm{m})\left[\mathrm{g} 1+\frac{\mathrm{e}^{-\mathrm{disdel} \cdot \text { Delta }}-\mathrm{e}^{-\mathrm{disdel} \cdot \mathrm{xbl}}}{1-\mathrm{e}^{- \text {disdel } \cdot \text { Delta }}} \mathrm{g}+\mathrm{g} 2 \mathrm{e}^{-\mathrm{disdel} \cdot \mathrm{xbl} l}\right] \ldots
$$

Abbreviating the factor in the bracket as g5, and restoring VPN, Eq. (68) becomes

$$
\begin{array}{r}
\operatorname{prna}(n, m)=\operatorname{Pout}(m) \cdot g 3+g \sum_{i=1}^{i b l-1} g 0^{i} \cdot\left(1-h^{i}\right) \cdot \operatorname{Pout}(m+i)+g 2 \cdot g 0^{i b l}\left(1-h^{i b l}\right) \cdot \operatorname{Pout}(m+i b l) \\
-(o m(n) \cdot \operatorname{olearn}(m)+V P N) \cdot g 5+\frac{s c c(n) \cdot \operatorname{pvfci}(n) \cdot \operatorname{pvfct}(m) \cdot \operatorname{shexp}(n)}{(1-\operatorname{Taxr})} .
\end{array}
$$

Before proceeding further, we must address the issue of the horizon price. This price is also derived from Eq. (41) using that expression for $n=N$ per. There are two cases to consider: the first simply sets the horizon period equal to Nper and the rent at that point equal to zero; the second allows the calculation to proceed past $N$ per. In that case, values for $\operatorname{scc}(\mathrm{m})$ and $\mathrm{om}(\mathrm{m})$ continue past $\operatorname{Nper}(\mathrm{m}>\mathrm{Nper})$ until $\mathrm{m}=60$ or the selling price becomes less than a user-supplied backstop price. In either case, the horizon price is derived from Eq. (41) in much the same way as was done for Eq. (68). If nhor is the horizon period,

$$
\text { Pout(nhor) }=\text { olearn(nhor') } \cdot \text { om(nhor })+ \text { VPN }-\frac{\operatorname{scc}(\text { nhor }) \text { pvfci(nhor)pvfct(nhor' }) \cdot \text { disdel }}{\left(1-\mathrm{g}^{\text {ibl }}\right) \cdot(1-\text { Taxr })}
$$

where

$$
\text { nhor }^{\prime}=\operatorname{MIN}(\text { nhor,Nper })
$$


Note that learning and secondary-material factors in periods beyond $N$ per are set equal to those at $N$ per and the shutdown-expansion submodel is inoperative. If calculations are proceeding past Nper, nhor is determined when

$$
\text { HPRICE < Pout(nhor) }
$$

for some value of nhor (or nhor $=60$ ). Once Pout(nhor) is determined, the algorithm works backward to get pima(n,m) for all $n$ and $m$.

Note that pma(n,m) is the actual calculated future profit margin. In the same way as developers were not allowed perfect knowledge of future prices, resource owners are given "fuzzy" foresight by making the perceived profit margin $\mathrm{pmp}(\mathrm{n}, \mathrm{m})$, a combination of the actual (known) future profit margins and the present period profit margin (unknown). More precisely,

$$
\operatorname{pmp}(n, m)=e^{-S M R E N T} \cdot \operatorname{Delta} \cdot(i-n) \cdot p m a(n, n)+\left(1-e^{-S M R E N T \cdot \operatorname{Delta}(i-n)}\right) \cdot p m a(n, m)
$$

The present value in period $\mathrm{n}$ of the perceived profit margin is

$$
\operatorname{pvpmp}(n)=\operatorname{pmp}(n, m) e^{-D R E N T \cdot D e l t a(i-n)}
$$

where

DRENT = the resource owner's real discount rate,

SMRENT = a mixing parameter, analogous to that for the developer's (SMOOTH).

To get the value for the rent to be charged in period $n, \operatorname{Rent}(n)$, we must solve Eq. (66):

$$
\begin{aligned}
& \operatorname{Rent}(n)=\underset{n}{\operatorname{MAX}}\left[\mathrm{e}^{- \text {DRENT} \cdot \text { Delta } \cdot(i-n)} \cdot \mathrm{e}^{- \text {SMRENT} \cdot \text { Delta } \cdot(i-n)} \cdot \operatorname{ppa}(n, n)\right. \\
& \left.+\left(1-\mathrm{e}^{-S M R E N T} \cdot \operatorname{Delia} \cdot(i-n)\right) \cdot p p a(n, m)\right] .
\end{aligned}
$$

As Rent(n) is just another way of writing ppa(n,n), Eq. (74) is of the form

$$
x=\underset{i}{\operatorname{MAX}}\left(A_{i} x+B_{i}\right)
$$

Assuming $x=A_{j} x+B_{j}$ (that is, the maximum occurs when $i=j$ ), then

$$
\begin{aligned}
& x=\frac{B_{j}}{1-A_{j}} \text {, so } \\
& x=M_{i} X \frac{B_{j}}{1-A_{j}} \text {, and the solution of Eq. (74) is }
\end{aligned}
$$




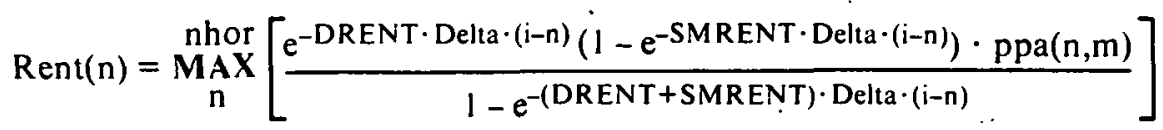

Since Rent(n) = pma(n,n), once Eq. (75) has been solved, the result can be inserted in Eq. (70), with $m$ set equal to $n$, and the resulting expression solved for the total selling price, including rent.

$$
\begin{gathered}
\text { Pout }(n)=\left\{\operatorname{Rent}(n)-g \sum_{i=1}^{i b l-1} g 0^{0}\left(1-h^{i}\right) \operatorname{Pout}(n+i)\right. \\
-g 2 \cdot g 0^{i b l}\left(1-h^{i b l}\right) \cdot \operatorname{Pout}(n+i b l)+\left[0 m(n) \cdot \operatorname{olearn}\left(n^{\prime}\right)+V P N\right] \cdot g 5 \\
\left.-\frac{\operatorname{scc}(n) \cdot \operatorname{pvfci}\left(n^{\prime}\right) \cdot \operatorname{pvfct}\left(n^{\prime}\right) \cdot \operatorname{shexp}\left(n^{\prime}\right)}{(1-\operatorname{Taxr})}\right\} / g 3,
\end{gathered}
$$

where

$$
\mathbf{n}^{\prime}=\operatorname{MIN}(\mathrm{n}, \mathrm{Nper})
$$

Since the algorithm first calculates the horizon price Pout(nhor) and then works backwards, Pout(n + i) and Pout(n + ibl) are always known and Eq. (76) can be solved.

\section{Quantity Calculation}

There are no primary energy inputs to the resource process. The secondary inputs, given by

$$
Q \sec (i, n)=\operatorname{con}(n) \cdot S F(i) \cdot \operatorname{scc}(n) \cdot \operatorname{clearn}(n) \cdot \operatorname{caf},
$$

are handled in the same way as in SIMPLE.

\section{Submodels OLDRESOURCE and RESSL}

Submodel OLDRESOURCE is a simplified version of RESUURCE in which no capital costs appear-that is, scc $=0$ in each period. The operating and maintenance costs array, $O M(k)$, and cumulative committed capacity array, QTY(k), contain all information concerning development costs, including the developer's return on investment. Put another way, the total developer's price is simply picked off the OM versus QTY arrays at the place determined by the cumulative committed capacity, $q c(n)$. Shutdown-expansion and secondary-materials factors are included by setting

$$
o m(n)=o m^{\prime}(n) \cdot \operatorname{shexp}\left(n^{\prime}\right) \cdot \operatorname{smfact}\left(n^{\prime}\right),
$$


where

$$
\begin{aligned}
\text { om' }^{\prime}(n)= & \text { the operating and maintenance value obtained from the OM versus QTY arrays by } \\
& \text { use of Eas. (59), (60) and (61), } \\
n^{\prime} & \text { MIN(n,Nper) }
\end{aligned}
$$

Note that clearn(n) has been set to unity.

Submodel RESSL is identical to OLDRESOURCE except that it allows an operating learning factor, olearn(n), in Eq. (77).

Derivation of the output prices proceeds exactly as in submodel RESOURCE, except that the terms containing $\operatorname{scc}(\mathrm{n})$ in Eqs. (71) and (76) are absent.

There is one point about the use of OLDRESOURCE and RESSL that should be made. Penalties for extraction of a resource before its nominal year of availability, YRAVL, are included in factors multiplying $\operatorname{scc}(n)$. Since $\operatorname{scc}(n)$ is always zero, these penalties must be enforced in a different way. The modeler should insert a process node in the network just above the resource node and bind a submodel to that new node in which YRAVL penalties are effective. Submodel TRIVIAL is an efficient process to use for this purpose. 


\section{APPENDIX A. CALCULATIONS FOR NPVDCF AND FOR INITIALIZATIION OF EQ. (64a)}

\section{SECTION 1-CALCULATIONS FOR NET PRESENT VALUE DISCOUNTED CASH FLOW (NPVDCF)}

All investors, large or small, expect to receive some return on their money. The NPVDCF calculation serves as a method of evaluating various investment opportunities.

The simplest example that comes to mind is that of a bank account returning an interest rate $i$. If an amount $\mathrm{P}$ is placed in that account, $\mathrm{n}$ compounding periods later $\mathrm{P}$ has grown to a value $\mathrm{R}$ given by

$$
R=P(1+i)^{n}
$$

Given any two of the parameters $P, R$, or $i$ (assuming a fixed $n$ ) the third can be found from Eq. (Al.1). For example, suppose the return $R$ and interest rate $i$ are known, then the principal, $P$, required to generate $R$ at the rate $\mathrm{i}$ is obtained by inverting Eq. (Al.1) and solving the expression

$$
P-R(1+i)^{-n}=0
$$

Equation (A1.2) was purposely written in this strange way to introduce some terminology.

1. The process of compounding backward in time with the expression $(1+i)^{-n}$ is called discounting. As a matter of fact, compounding forward in time is also usually called discounting as well to avoid undue concern over which way the $(1+i)^{-n}$ is being applied.

2. Discounting an amount of money to some time is called "getting the present value." Equation (A 1.2) gets the present value at time zero (now) of the future amount $R$. However, the present value can be at any time, say after $m$ compounding periods. That is, the principal, $P$, can be discounted forward $m$ periods and the return $R$ need be discounted only $n-m$ periods, so that the expression for the present value at period $\mathbf{m}$ is

$$
P(1+i)^{m}-R(1+i)^{-(n-m)}=0
$$

which is, of course, the same as. Eq. (A 1.2).

3. What we have done is specify the cash flows-the investment outflow, $P$, and the return inflow, $\mathrm{R}$-and discount them to some common time which we have termed "the present time."

4. By writing the sum of the discounted cash flows, with inflows and outflows having a different algebraic sign, in the form of Eq. (A 1.2), we have formed the Net Present Value of the Discounted Cash Flows (NPVDCF). And that is all there is to it! 
Of course, a developer planning to spend millions of dollars on some sort of plant has more factors which must be considered. Cash outflows over the life of a plant include:
a. Capital costs of construction.
b. Operating and maintenance costs.
c. Interest payments on any borrowed money.
d. Taxes and insurance.
e. Fuel costs.

Cash flow inflows include:

a. Tax credits and write-offs (depreciation).

b. Income.

However, the principle of the NPVDCF calculation remains the same. All cash flows are discounted to a common time and added with the correct sign, to yield an equation of the form

$$
\text { Net Present Value }=0 \text {, }
$$

which can be solved for whatever unknown remains.

The last point that needs to be mentioned is that continuous rather than discrete discounting is used in EMS. $(1+i)^{n}$ is replaced by $e^{\text {nij }}$ where $j$ is the continuous analog of the discrete rate, $i$. The main reason for the use of continuous discounting is that simple, closed forms for the NPVDCF equations can be derived.

\section{SECTION 2-INITIALIZATION OF CUMULATIVE COMMITTED CAPACITY FOR RESOURCES-EQ. (64a)}

It is assumed that plants constructed in each of the ibl periods before the problem's first period are still producing resources at a constant rate equal to that of when they were built. Thus, the remaining committed capacity at $n=1$ is the sum of the product of capacity times remaining production time for each facility.

$$
q c(1)=\sum_{n=0}^{i b l-1} \operatorname{con}(1-n) \cdot(i b l-n) \cdot \text { Delta }^{*}
$$

Assuming a constant growth rate $\mathrm{r}$, the derivation of Eq. (1.1) holds. So

$$
\operatorname{con}(n)=\frac{\ddot{K}(r-1) r^{\mathrm{ibl} l-1+m}}{r^{\mathrm{ibl}}-1}=\frac{\text { Qout }(1)(r-1) r^{\mathrm{ibl}+n-2}}{\mathrm{r}^{\mathrm{ibl}}-1},
$$

since Qout $(1)=\mathrm{Kr}$.

* Recall that subscripts $\leqslant 0$ are used for periods before the start of the problem. 
Equation (A2.2) can be substituted into Eq. (A2.1). [Note that Eq. (A2.1) requires con(1 - n).]

$$
q c(1)=\frac{\text { Qout }(1)(r-1) r^{i b l-1}}{r^{i b l}-1} \sum_{n=0}^{i b l-1} i b l r^{-n}-\sum_{n=0}^{i b l-1} n r^{-n} \cdot \text { Delta }
$$

This expression sums to

$$
q c(l)=\frac{\text { Qout }(1)}{\left(r^{i b l}-1\right)(r-1)}\left[r^{i b l}(i b l \cdot r-i b l-1)+1\right] \cdot \text { Delta }
$$

Possible production losses must be accounted for by dividing Eq. (A2.3) by the effective first period efficiency, EFF - elearn(1). The result is the $r \neq 1$ part of Eq. (64a).

If $\mathrm{r}=1$, it is assumed that

$$
\operatorname{con}(n)=w(n)=\frac{\text { Qout }(1)}{i b l}
$$

Use of Eq. (A2.4) rather than (A2.2) in (A2.1) yields $q c(1)=1 / 2(\mathrm{ibl}+1) \cdot$ Qout $(1)$ and, thus, the other half of Eq. (64a).

\section{REFERENCES}

1. R. B. Bell, A Study of Foresight Modeling Using the LLNL Economic Modeling System, Lawrence Livermore National Laboratory, Rept. UCID-18794 (1980).

2. R. B. Bell, The Market Share Algorithm Used in the Livermore Economic Modeling System, Lawrence Livermore National Laboratory, Rept. UCID-18914 (1981).

3. C. J. Anderson, R. Castleton, B. Coles, and J. Rambo, A Demonstration of the Capabilities of the Livermore Energy Policy Model: An Update, Lawrence Livermore National Laboratory, Rept. UCRL-52508 (1979).

4. S. S. Sussman and W. F. Rousseau, A New Language for Economic General Equilibrium Models, Lawrence Livermore National Laboratory, Rept. UCRL-52507 (1978).

5. S. S. Sussman and W. F. Rousseau, A Demonstration of the Capabilities of the Livermore Energy. Policy Model, Lawrence Livermore National Laboratory, Rept. UCRL-52508 (1978).

6. W. F. Rousseau, J. T. Rambo, R. N. Castleton, and S. S. Sussman, Computer Code Documentation for the Livermore Economic Modeling System, Lawrence Livermore National Laboratory, Rept. UCRL52519 (1978).

7. J. T. Rambo and B. L. Coles, User's Manual for the Livermore Economic Modeling System. Lawrence Livermore National Laboratory, Rept. UCRL-52526 (1978).

8. W. F. Rousseau, S. S. Sussman, R. N. Castleton, and J. T. Rambo, Economic Models and Algorithms Used in the Livermore Economic Modeling System, Lawrence Livermore National Laboratory. Rept. UCRL-52527 (1978).

$\mathrm{DPH} / \mathrm{ss} / \mathrm{jvb}$ 
Technical Information Department . Lawrence Livermore National Laboratory University of California - Livermore, California 94550

\section{First Class Mail}

